\title{
Phasic Dopamine Modifies Sensory-Driven Output of Striatal Neurons through Synaptic Plasticity
}

\author{
Sebastian Wieland, Sebastian Schindler, Cathrin Huber, Georg Köhr, ${ }^{\circledR}$ Manfred J. Oswald, and $\odot$ Wolfgang Kelsch \\ Central Institute of Mental Health, Medical Faculty Mannheim, Heidelberg University, 68159 Mannheim, Germany
}

\begin{abstract}
Animals are facing a complex sensory world in which only few stimuli are relevant to guide behavior. Value has to be assigned to relevant stimuli such as odors to select them over concurring information. Phasic dopamine is involved in the value assignment to stimuli in the ventral striatum. The underlying cellular mechanisms are incompletely understood. In striatal projection neurons of the ventral striatum in adult mice, we therefore examined the features and dynamics of phasic dopamine-induced synaptic plasticity and how this plasticity may modify the striatal output. Phasic dopamine is predicted to tag inputs that occur in temporal proximity. Indeed, we observed $\mathrm{D}_{1}$ receptor-dependent synaptic potentiation only when odor-like bursts and optogenetically evoked phasic dopamine release were paired within a time window of $<1 \mathrm{~s}$. Compatible with predictions of dynamic value assignment, the synaptic potentiation persisted after the phasic dopamine signal had ceased, but gradually reversed when odor-like bursts continued to be presented. The synaptic plasticity depended on the sensory input rate and was input specific. Importantly, synaptic plasticity amplified the firing response to a given olfactory input as the dendritic integration and the firing threshold remained unchanged during synaptic potentiation. Thus, phasic dopamine-induced synaptic plasticity can change information transfer through dynamic increases of the output of striatal projection neurons to specific sensory inputs. This plasticity may provide a neural substrate for dynamic value assignment in the striatum.
\end{abstract}

Key words: olfaction; odor; striatum; D1; olfactory tubercle

\section{Introduction}

The striatum has evolved as a centralized device for value assignment to stimuli, specialized to resolve conflicts of environmental stimuli for access to limited cognitive resources (Redgrave and Gurney, 2006). The striatum is the main projection target of dopaminergic midbrain neurons. Dopaminergic neurons fire synchronous bursts with a short latency of 50-110 ms following novel stimuli and reward-associated events (Ljungberg et al., 1992; Bromberg-Martin et al., 2010). If novel stimuli are not reinforced, burst responses of dopaminergic neurons gradually disappear (Schultz, 1986).

In the striatum, phasic dopamine (pDA) release is thought to act as a selection mechanism through which one sensory input becomes dominant over concurring inputs (Kapur, 2003). pDA release provides a transient signal that can causally influence cueelicited reward-seeking behavior (Steinberg et al., 2013). In the dorsal striatum and nucleus accumbens, DA receptor (DAR) ac-

Received Jan. 10, 2015; revised May 5, 2015; accepted June 1, 2015.

Author contributions: S.W., C.H., G.K., M.J.O., and W.K. designed research; S.W., S.S., C.H., M.J.O., and W.K. performed research; C.H. and W.K. contributed unpublished reagents/analytic tools; S.W., S.S., C.H., M.J.O., and W.K. analyzed data; S.W., G.K., and W.K. wrote the paper.

The project was funded by the Deutsche Forschungsgemeinschaft Emmy-Noether-Program KE1661/1-1, DFG SFB636 TP B08, and DFG SPP1665 Resolving and Manipulating Neuronal Networks KE1661/2-1 to W.K. We thank Drs. C. Savio Chan and D. James Surmeier for gift of the mouse primers, Dr. Hannah Monyer for providing D2-GFP mice, and Dr. Andreas Meyer-Lindenberg for his support.

The authors declare no competing financial interests.

Correspondence should be addressed to Dr. Wolfgang Kelsch, Central Institute of Mental Health, Medical Faculty Mannheim, Heidelberg University, 68159 Mannheim, Germany. E-mail: wolfgang.kelsch@zi-mannheim.de.

DOI:10.1523/JNEUROSCI.0127-15.2015

Copyright $\odot 2015$ the authors $\quad 0270-6474 / 15 / 359946-11 \$ 15.00 / 0$ tivation is critical to many forms of long-term potentiation (Kerr and Wickens, 2001; Calabresi et al., 2007; Kreitzer and Malenka, 2008; Shen et al., 2008; Bateup et al., 2010; Shan et al., 2014). For instance, pulsatile application of exogenous DA coincident with presynaptic stimulation results in $D_{1}$ receptor $\left(D_{1} R\right)$-dependent synaptic potentiation (Wickens et al., 1996) as does the electrical stimulation of midbrain neurons (Reynolds et al., 2001). These studies had revealed a central role of DA in synaptic plasticity, yet the cellular mechanisms by which temporally controlled endogenous pDA release acts on sensory inputs are incompletely understood.

Phasic DA-induced plasticity is predicted to have a number of properties. Sensory stimuli that occur in temporal proximity to the pDA signal should be strengthened, and this potentiation should be reversible if the stimulus is no longer reinforced by the pDA signal. To test these predictions, we examined plasticity induced by pDA release on sensory inputs in the olfactory tubercle (OTu) of the ventral striatum. In human imaging studies, the OTu is selectively activated in response to attended odors, but not to unattended odors (Zelano et al., 2005). In the OTu, striatal projection neurons (SPNs) are clustered in layer 2 and receive direct sensory inputs from the main olfactory bulb (Wieland et al., 2014). In vivo, odors evoke time-locked increases in the firing rate of putative SPNs (Wesson and Wilson, 2010).

Since SPNs directly project to other brain regions (Wesson and Wilson, 2011), we examined potential modifications of the firing output evoked by a constant sensory input that was transiently paired with pDA. Toward this aim, we used optogenetically evoked pDA release on olfactory inputs to SPNs in whole-cell recordings from slices of the adult mouse OTu and 
observed plasticity consistent with predictions for dynamic value assignment of stimuli. Importantly, pDA modified sensory-driven firing output through synaptic potentiation, since dendritic integration and somatic excitability remained unchanged. This plasticity provides a mechanism through which pDA can increase the gain of the output of neurons responding to potentially relevant stimuli.

\section{Materials and Methods}

Animals and husbandry. We used heterozygous transgenic mice $\mathrm{Tg}$ (DATCre)9075Gsc (Parlato et al., 2006) expressing the Cre recombinase under control of the dopamine transporter (DAT) gene contained in a bacterial artificial chromosome (DAT-Cre). DAT-Cre mice were maintained on a C57BL/6NCrl background (Charles River). D1dTomato mice (Ade et al., 2011) and D2-GFP mice (Gertler et al., 2008) were bred with C57BL/6NCrl wild-type mice. Two to four mice were housed per cage, were kept on a standard $12 \mathrm{~h}$ light/dark cycle, and were given food and water ad libitum. All animal procedures were approved by the local Animal Welfare Committee and in accordance with National Institutes of Health guidelines. Throughout the study, mice of either sex were used.

Virus preparation and stereotactic injection. To generate cell typespecific expression of channelrhodopsin 2 (ChR2), we injected a Cre-inducible recombinant adeno-associated virus (AAV) vector pAAV-double floxed(DIOA)-ChR2:mCherry (Cardin et al., 2009) into heterozygous DAT-Cre mice (Parlato et al., 2006; Wieland et al., 2014). Cre-inducible recombinant AAV vectors were produced with $\mathrm{AAV}_{1 / 2}$ coat proteins to a final viral concentration of $\sim 10^{16}$ genome copies $/ \mathrm{ml}$. Mice $>8$ weeks of age were anesthetized with isoflurane; and $0.75 \mu \mathrm{l}$ of purified double-floxed $\mathrm{rAAV}_{1 / 2}$-DIOA-ChR2:mCherry virus was injected into each hemisphere of the ventral midbrain (location from bregma: posterior, $3.0 \mathrm{~mm}$; lateral, $0.8 \mathrm{~mm}$; ventral, $4.4 \mathrm{~mm}$ ). All mice recovered for at least $21 \mathrm{~d}$ before undergoing electrophysiological experiments.

Laser stimulation. TTL-driven laser pulses ( $5 \mathrm{~ms}$ duration, $5-10 \mathrm{~mW} /$ $\mathrm{mm}^{2}$ at slice) were delivered from $100 \mu \mathrm{m}$ multimode optical fibers (THORLABS) coupled to a $25 \mathrm{~mW}, 473 \mathrm{~nm}$, diode-pumped solid-state laser (CrystaLaser). The fiber optic was positioned at a distance of $>300$ $\mu \mathrm{m}$ from the recording site. Laser light pulses did not produce any detectable postsynaptic responses in eight $\mathrm{SPNs}$ in $\mathrm{ChR} 2{ }^{-}$mice.

Electrophysiology. Animals were given an overdose of isoflurane and were perfused intracardially with cold $\left(4^{\circ} \mathrm{C}\right)$ slicing solution containing the following (in mM): 212 sucrose, $3 \mathrm{KCl}, 1.25 \mathrm{NaH}_{2} \mathrm{PO}_{4}, 26 \mathrm{NaHCO}_{3}, 7$ $\mathrm{MgCl}_{2}$, and 10 glucose, at $308 \mathrm{mOsm}, \mathrm{pH}$ 7.3. The $300 \mu \mathrm{m}$ coronal or sagittal sections were cut in a cold slicing solution with a vibratome (Microm). For recovery, slices were incubated at $32^{\circ} \mathrm{C}$ for $30 \mathrm{~min}$ in carbogenated artificial CSF (ACSF) containing the following (in $\mathrm{mm}$ ): $125 \mathrm{NaCl}, 2.5 \mathrm{KCl}, 1.25 \mathrm{NaH}_{2} \mathrm{PO}_{4}, 25 \mathrm{NaHCO}_{3}, 1 \mathrm{MgCl}_{2}, 2 \mathrm{CaCl}_{2}$, and 25 glucose, at $312 \mathrm{mOsm}, \mathrm{pH}$ 7.3. Infrared differential interference contrast patch-clamp recordings were performed with an EPC-10USB amplifier (HEKA). If not otherwise mentioned, the pipet solution for whole-cell recordings contained the following (in $\mathrm{mM}$ ): $120 \mathrm{~K}$-gluconate, $10 \mathrm{HEPES}$, $15 \mathrm{KCl}, 4 \mathrm{Mg}$-ATP, 7 Phosphocreatine, 4 ATP-Mg, $0.3 \mathrm{GTP}$, and 0.1 EGTA, at $291 \mathrm{mOsm}, \mathrm{pH}$ 7.2. The recording solution (physCSF) contained the following (in mM): $125 \mathrm{NaCl}, 3.5 \mathrm{KCl}, 1.25 \mathrm{NaH}_{2} \mathrm{PO}_{4}, 25$ $\mathrm{NaHCO}_{3}, 1 \mathrm{MgCl}_{2}, 1 \mathrm{CaCl}_{2}$, and 25 glucose, 312 mOsm, pH 7.3. Comparing the solutions, physCSF had a lower concentration of $\mathrm{CaCl}_{2}$ and a higher concentration of KCl than ACSF (Shu et al., 2003).

Initially, we compared excitability of SPNs in ACSF and physCSF. When ACSF was replaced during the recording by physCSF, the resting membrane potential $\left(V_{\mathrm{m}}\right)$ changed from $-89.3 \pm 0.6$ to $-79.3 \pm 0.9 \mathrm{mV}$ ( $p<0.05, t$ test), while the input resistance remained stable (76.8 \pm 5.7 and $75.0 \pm 4.8 \mathrm{M} \Omega ; p=$ n.s., $t$ test; $n=10 \mathrm{SPNs}$ ). Also, the intracellular current required to evoke action potentials (APs) decreased from $340.9 \pm 21 \mathrm{pA}\left(V_{\mathrm{m}}=-43.8 \pm 1.0 \mathrm{mV}\right)$ in ACSF to $302.3 \pm 11.9 \mathrm{pA}$ in physCSF $\left(V_{\mathrm{m}}=-46.8 \pm 0.9 \mathrm{mV}\right.$; both $p<0.05, t$ test; $\left.n=10\right)$. All subsequent recordings were therefore performed in physCSF and at $33^{\circ} \mathrm{C}$. Pipette resistance ranged from 4 to $7 \mathrm{M} \Omega$, and cells were only accepted for analysis if pipet access resistance was $<25 \mathrm{M} \Omega$. Throughout the study, the junction potential was not corrected and input resistance was monitored by current steps $(50 \mathrm{~ms},-30 \mathrm{pA})$. Cells were excluded if the input resistance changed by $>20 \%$ during the recording. Data were acquired with Patchmaster software (HEKA) and analyzed with IgorPro software (Wavemetrics). 4-AP, SKF38393, SCH23390, sulpiride, and atropine were purchased from Sigma-Aldrich; and dihydro- $\beta$ erythroidine $(\mathrm{DH} \beta \mathrm{E})$ was purchased from Tocris Bioscience. CNQX, $\mathrm{D}-\mathrm{AP} 5$, and gabazine were purchased from Biotrend.

SPNs were targeted with DIC microscopy based on their small oval somata in layer 2. Membrane capacitance and resistance were determined by application of a hyperpolarizing pulse of $10 \mathrm{mV}$ for $10 \mathrm{~ms}$. For the initial characterization of layer 2 neurons, action potential firing was recorded in current-clamp mode at injected current $I_{\text {inj }}=0$ pA by application of a rectangular $1 \mathrm{~s}$ current steps starting at $I_{\text {inj }}=-200 \mathrm{pA}$ up to saturation (step size $=50 \mathrm{pA}$ ).

The AP threshold was determined by applying a 2-s-long ramp current injection following a $0.5 \mathrm{~s}$ subthreshold current step to achieve a starting membrane potential of approximately $-60 \mathrm{mV}$. Phasic laser stimulation (PLS; $40 \mathrm{~Hz}, 300 \mathrm{~ms}$ ) and no-PLS trials were repeated at least 15 times at an interval of $20 \mathrm{~s}$ in an alternating fashion. PLS was applied in two sets of experiments starting either "early" (200 ms before ramp onset) or "late" (1 s after ramp onset). Injected current was initially adjusted so that the first AP occurred only $>1 \mathrm{~s}$ after ramp onset to ensure that AP firing did not start before late PLS. We applied a threshold of $1 \mathrm{~V} / \mathrm{s}$ to determine the membrane potential at which the first AP was initiated in each trial and compared the averaged AP threshold for each condition.

Electrical stimulation. To record evoked EPSPs from the lateral olfactory tract (LOT), a unipolar glass stimulation electrode was positioned in the superficial parts of layer 1 of the OTu. All recordings involving electrical stimulation were performed in the presence of gabazine $(10 \mu \mathrm{M})$. EPSP amplitude was measured from baseline to peak. EPSP latency was measured as the time between the onset of the electrical stimulation to the deflection of EPSP rising phase from baseline. Paired-pulse ratios (PPRs) were obtained by dividing the second EPSP amplitude by the first EPSP amplitude. The slope of the EPSP was determined between $20 \%$ and $80 \%$ of the EPSP amplitude. Under our recording conditions $\left(V_{\mathrm{m}} \leq\right.$ $-80 \mathrm{mV}$ ), the block of NMDARs (D-AP5, $50 \mu \mathrm{M}$ ) had no effect on EPSP amplitude or slope (see Fig. 3D). We observed similar responses for stimulations in sagittal and coronal slices, and throughout the mediolateral and rostrocaudal extent of the OTu (Wieland et al., 2014).

For plasticity induction by the $\mathrm{D}_{1} \mathrm{R}$ agonist or PLS, we stimulated the LOT with paired pulses (two pulses with an interstimulus interval of 20 ms) every $20 \mathrm{~s}$. After obtaining a stable baseline, OSTIM ( $100 \mathrm{~Hz}$ for 500 ms every $20 \mathrm{~s}$ ) was applied 15 times in the presence of $D_{1} R$ agonist or coincident PLS. We then switched back to paired-pulse stimulation. For parallel stimulation of the control pathway (L.3 stim), a second unipolar glass stimulation electrode was positioned in layer 3 to evoke paired pulses. We tested for AP dependence of plasticity induction by applying a subthreshold stimulation ("low-intensity stimulation") versus OSTIM ("high-intensity stimulation"). To control for plasticity-induced changes of intrinsic excitability, we evoked AP firing by somatic current-step injections before and after the plasticity experiment in neurons that showed an EPSP potentiation and measured AP threshold and rheobase. The rheobase (current required to evoke an $\mathrm{AP}$ ) was determined from the $x$-intercept of linear fits of the respective "current input - spike output" curves before and after the plasticity experiment.

Odor-like stimulation and analysis. We performed current-clamp whole-cell recordings in layer 2 SPNs and stimulated with the following paradigm: control EPSPs (two pulses with an interstimulus interval of 20 ms) were separated by $10 \mathrm{~s}$ from the OSTIM ( $100 \mathrm{~Hz}$ for $500 \mathrm{~ms})$. While continuously applying the OSTIM protocol every $20 \mathrm{~s}$, neurons required 5-10 min to reach a steady state of cumulative discharge (see Fig. 2C). We continued with the OSTIM for another $5 \mathrm{~min}$ ("pre") before we switched to the OSTIM-PLS pairing. PLS ( $40 \mathrm{~Hz}$ for $400 \mathrm{~ms}$ ) started $100 \mathrm{~ms}$ after OSTIM onset. The OSTIM-PLS pairing was repeated 15 times. After the pairing, only the OSTIM was applied to examine potentially longerlasting effects of pDA. Throughout the experiment, the EPSP amplitude, $\mathrm{PPR}$, and the input resistance were monitored. To test for effects of 
background input from the olfactory bulb [background stimulation (BSTIM)], the PLS was paired with BSTIM (20 Hz for $500 \mathrm{~ms})$. For noncoincident pairing, PLS started either $1 \mathrm{~s}$ before the start or after the end of OSTIM. AP frequencies were measured as the number of APs within $500 \mathrm{~ms}$ during which OSTIM was applied. Stimulation intensity and location were kept constant throughout the recording. For analysis, we averaged EPSPs and AP frequencies of the first $5 \mathrm{~min}$ after the end of the OSTIM-PLS pairing (post 1) and compared them to their baseline OSTIM (pre). Pre was defined as the 5 min before the start of OSTIMPLS pairing. Amplitude-to-slope ratios were calculated for individual EPSPs and then averaged. For AP threshold analysis during each OSTIM, we measured the membrane potential at which the first AP occurred.

Biocytin filling of neurons and reconstruction. Brain slices of adult mice were prepared as described for electrophysiology. Neurons were recorded with $2 \mu \mathrm{g} / \mathrm{ml}$ biocytin in the pipet for 10-30 min. After the pipet was withdrawn, slices were kept in the recording chamber for an additional 10 min and subsequently were immersion fixed in $4 \%$ PFA at $4{ }^{\circ} \mathrm{C}$ overnight. Biocytin-filled cells were incubated with peroxidase-avidinbiotin complex (Vector Laboratories) and visualized with DAB-nickel sulfate (Sigma-Aldrich). Subsequently, slices were mounted onto microscope slides and coverslipped with Mowiol. The reconstruction of biocytin-filled neuron was performed with a Neurolucida System (MBF Bioscience) with $100 \times$ oil-immersion objective (Imager, Zeiss).

Immunohistochemistry. Mice were given an overdose of isoflurane and perfused transcardially with $\mathrm{PBS}$ at $37^{\circ} \mathrm{C}$; subsequently, they were perfused with $4 \%$ PFA and post-fixed in $4 \%$ PFA for $12 \mathrm{~h}$ at $4^{\circ} \mathrm{C}$. Slices were cut with a vibratome. In D2-GFP mice, sections were incubated in blocking solution containing primary rabbit antibody raised against GFP (1: 3000; Millipore) at $4^{\circ} \mathrm{C}$ overnight and Alexa Fluor 488-conjugated secondary antibody (1:1.000; Invitrogen) at room temperature (RT) for 2 h. Blocking solution contained $0.25 \%$ Triton X and $1 \%$ fetal bovine serum (FBS). Sections were mounted with Fluoromount (SigmaAldrich) and analyzed using a confocal laser scanning microscope (SPM5, Leica). Single confocal sections $(63 \times$ oil-immersion) were taken from $50 \mu \mathrm{m}$ coronal sections of the OTu per mouse. The extent of D2GFP and D1-dTomato expression and their colocalization were determined in layer 2 (excluding the Islands of Calleja).

Single-cell PCR. Acute coronal slices of 20- to 40-d-old D1-dTomato mice were prepared as described for electrophysiological recordings. The recovery solution containing the following (in $\mathrm{mm}$ ): $125 \mathrm{NaCl}, 2.5 \mathrm{KCl}$, $1.25 \mathrm{NaH}_{2} \mathrm{PO}_{4}, 25 \mathrm{NaHCO}_{3}, 4 \mathrm{MgCl}_{2}, 1 \mathrm{CaCl}_{2}, 25$ glucose, 0.05 D-AP-5, and $0.01 \mathrm{CNQX}$, at $312 \mathrm{mOsm}, \mathrm{pH} 7.3$. After $30 \mathrm{~min}$ of recovery at $32^{\circ} \mathrm{C}$, $1 \mathrm{mg}$ of Pronase (Sigma P8811) was added per milliliter of recovery solution, and slices were kept at RT for $1 \mathrm{~h}$. Slices were then transferred to a recovery solution with $1 \% \mathrm{FBS}$. After $30 \mathrm{~min}$, tissue was dissected and triturated with glass Pasteur pipets in modified Neurobasal medium containing the following (in mM): $5.3 \mathrm{KCl}, 0.4 \mathrm{KH}_{2} \mathrm{PO}_{4}, 4.2 \mathrm{NaHCO}_{3}, 137.9$ $\mathrm{NaCl}, 0.3 \mathrm{Na}_{2} \mathrm{HPO}_{4}, 5.5$ glucose, 10.4 HEPES, $11 \mathrm{MgCl}_{2}, 44$ sucrose, 0.05 D-AP5, $0.01 \mathrm{CNQX}$, and 1\% FBS, pH 7.3. Cells were plated in $10 \mathrm{~cm}$ cell culture dishes and incubated at $37^{\circ} \mathrm{C}$ with $5 \% \mathrm{CO}_{2}$. Two gentle washing steps with the modified Neurobasal medium were performed every 10 min. dTomato ${ }^{+}$and dTomato ${ }^{-}$cells were picked from the $10 \mathrm{~cm}$ dish with glass capillaries containing $145 \mathrm{~mm} \mathrm{KCl,} 3 \mathrm{~mm} \mathrm{MgCl}_{2}, 5 \mathrm{~mm} \mathrm{HEPES}$, osmol $292 \mathrm{~mm}$ attached to a Burleigh micromanipulator fixed to a Zeiss inverted fluorescence microscope $(20 \times)$. The content of the capillary was expelled into the mix for cDNA synthesis containing $5.15 \mu \mathrm{l}$ of DEPC- $\mathrm{H}_{2} \mathrm{O}, 0.35 \mu \mathrm{l}$ of Rnasin (40 U/ $\mu \mathrm{l} ; \mathrm{N} 2511$, Promega), $0.5 \mu \mathrm{l}$ of DTT $(0.1 \mathrm{M})$, and $0.5 \mu \mathrm{l}$ of random hexanucleotides (500 ng/ $\mu \mathrm{l}$; N8080127, Invitrogen), and incubated at RT for $10 \mathrm{~min}$. The cDNA synthesis was performed by the addition of $1 \mu \mathrm{l}$ of SuperscriptII RT (200 U/ $\mu$ l; Invitrogen), $4 \mu \mathrm{l}$ of buffer (Superscript Kit), $0.35 \mu \mathrm{l}$ of Rnasin (40 U/ $\mu \mathrm{l}), 1.5$ $\mu \mathrm{l}$ of DTT $(0.1 \mathrm{M}), 0.5 \mu \mathrm{l}$ of dNTP mix ( $20 \mathrm{~mm}$; Bio\&Sell), and $0.65 \mu \mathrm{l}$ of DEPC- $\mathrm{H}_{2} \mathrm{O}$ per tube. Tubes were incubated at $42^{\circ} \mathrm{C}$ for $50 \mathrm{~min}$, followed by an inactivation step at $70^{\circ} \mathrm{C}$ for $15 \mathrm{~min}$ and then stored on ice. $\mathrm{RNaseH}$ ( $0.5 \mu \mathrm{l}$; catalog \#10334860, Fisher Scientific) was added at $37^{\circ} \mathrm{C}$ for 20 min. cDNA was stored at $-20^{\circ} \mathrm{C}$. In each round, cDNA was collected from a maximum of five dTomato ${ }^{+}$and 5 dTomato $^{-}$cells, and additionally from one negative control each containing only the cDNA synthesis mix and another negative control with collected Neurobasal medium, and a positive control with mRNA containing homogenate of the dorsal striatum. The latter positive control underwent cDNA synthesis in parallel with the picked cells. For PCR, the following primers were used to detect Substance P (GGGATGCTGATTCCTCAGTTG, TCGC GCTTCTTTCATAAGCC; fragment length, $153 \mathrm{bp}$ ); enkephalin (GAC TGCGCTAAATGCAGCTA, AAGAAGGCAGCTGTCCTTCA; fragment length, $91 \mathrm{bp}$ ); $\mathrm{D}_{1}$ R (TGCCGCTGTCATCAGGTTTC, AAAGGGCCAA AAGCCAGCAA; fragment length, $140 \mathrm{bp}$ ); and $\mathrm{D}_{2} \mathrm{R}$ mRNA (TTATGC CCTGGGTCGTCTATCT, ATGACAGTAACTCGGCGCTT; fragment length, $205 \mathrm{bp}$ ). Two rounds of PCR were performed. The first round contained $15 \mu \mathrm{l}$ of the cDNA template and a mix containing $5 \mu \mathrm{l}$ of $10 \times$ buffer, $8 \mu \mathrm{l}$ of $\mathrm{MgCl}_{2}$ (25 mM), $0.5 \mu \mathrm{l}$ of dNTPs $(20 \mathrm{~mm}), 2.5 \mu \mathrm{l}$ of DMSO, $0.25 \mu \mathrm{l}$ of TAQ polymerase $(5 \mathrm{U} / \mu \mathrm{l}), 10.75 \mu \mathrm{l}$ of water, and $1 \mu \mathrm{l}$ of each of the eight primers $(10 \mu \mathrm{M})$. Ten cycles were performed with decreasing annealing temperature $\left(1^{\circ} \mathrm{C}\right.$ per cycle; start, $94^{\circ} \mathrm{C}$ for $30 \mathrm{~s}, 63^{\circ} \mathrm{C}$ for $30 \mathrm{~s}$, $72^{\circ} \mathrm{C}$ for $\left.30 \mathrm{~s}\right)$, followed by 10 cycles $\left(94^{\circ} \mathrm{C}\right.$ for $30 \mathrm{~s}, 53^{\circ} \mathrm{C}$ for $30 \mathrm{~s}, 72^{\circ} \mathrm{C}$ for $30 \mathrm{~s})$. A second round was performed with $2 \mu \mathrm{l}$ of the first PCR product and a mix containing $2 \mu \mathrm{l}$ of $10 \times$ buffer, $1.6 \mu \mathrm{l}$ of $\mathrm{MgCl}_{2}(25 \mathrm{~mm}), 0.2 \mu \mathrm{l}$ of dNTPs $(20 \mathrm{~mm}), 1 \mu \mathrm{l}$ of DMSO, $0.2 \mu \mathrm{l}$ of TAQ polymerase $(5 \mathrm{U} / \mu \mathrm{l})$, $11.4 \mu \mathrm{l}$ of water, and $0.8 \mu \mathrm{l}$ of the primer $(10 \mu \mathrm{M})$ pair for each product. Fifteen cycles were performed with decreasing annealing temperature of $1^{\circ} \mathrm{C}$ per cycle (start, $94^{\circ} \mathrm{C}$ for $30 \mathrm{~s}, 63^{\circ} \mathrm{C}$ for $30 \mathrm{~s}, 72^{\circ} \mathrm{C}$ for $30 \mathrm{~s}$ ), followed by 15 cycles $\left(94^{\circ} \mathrm{C}\right.$ for $30 \mathrm{~s}, 53^{\circ} \mathrm{C}$ for $30 \mathrm{~s}, 72^{\circ} \mathrm{C}$ for $\left.30 \mathrm{~s}\right)$. The products were visualized on a $3 \%$ agarose gel. One positive sample of each of the four fragments was sequenced to assure the correct product.

Statistical analysis. Unless indicated otherwise, data were normally distributed and reported as the mean \pm SEM. Data were analyzed with the two-tailed Student's $t$ test or ANOVA with a post-test with Bonferroni correction for multiple comparisons.

\section{Results}

\section{Lateral olfactory tract inputs elicit bursts in SPNs}

We recorded from SPNs in layer 2 in an acute coronal slice preparation of the adult mouse OTu (Fig. $1 A-C$ ). SPNs had a resting membrane potential of $-82.4 \pm 0.5 \mathrm{mV}$ and an input resistance of $73.0 \pm 2.3 \mathrm{M} \Omega$, as well as a regular firing pattern with a slow ramp depolarization and a long latency to spike upon current injection ( $n=63$; Fig. $1 D)$. Reconstructions of biocytin-filled neurons with these properties revealed spiny dendrites $(n=5$; Fig. $1 C$ ). All recordings were performed in the presence of the $\mathrm{GABA}_{\mathrm{A}}$ receptor antagonist gabazine $(10 \mu \mathrm{M})$ to avoid confounding circuit effects on plasticity.

Single electrical stimuli to the LOT in the superficial parts of layer 1 evoked short-latency EPSPs (latency to EPSP onset $1.9 \pm$ $0.4 \mathrm{~ms}$ ) with paired pulse facilitation (PPR $2.2 \pm 0.3$ ) in SPNs $(n=10$; Fig. $1 E)$. EPSPs at a membrane potential of $-80 \mathrm{mV}$ were reversibly blocked by AMPAR/NMDAR antagonists $(n=$ 8). During odor presentation, olfactory bulb projection neurons fire bursts of $\sim 100 \mathrm{~Hz}$ for a few hundred milliseconds in awake mice (Uchida et al., 2014). We therefore applied short $100 \mathrm{~Hz}$ stimulations to the LOT. The $100 \mathrm{~Hz}$ LOT stimulation elicited trains of EPSPs that accumulated and evoked robust AP firing ( $n=15$; Fig. $1 F$; no spikes occurred spontaneously without LOT stimulation). LOT-evoked AP firing was reversibly blocked by the NMDAR antagonist $(n=4$; Fig. $1 F, G)$. Also, application of the AMPAR antagonist CNQX $(10 \mu \mathrm{M})$ entirely blocked AP firing in response to OSTIM $(17.3 \pm 3.9 \mathrm{~Hz}$ before vs $0.0 \pm 0.0$ $\mathrm{Hz}$ in CNQX, respectively; $n=6 \mathrm{SPNs}$ ). Thus, LOT activation elicits ionotropic glutamate receptor-dependent bursting in SPNs.

\section{Phasic DA release induces reversible potentiation}

To evoke endogenous pDA release, we conditionally expressed ChR2 in DAergic midbrain neurons (Fig. 1A). We injected a Cre-inducible AAV with double-floxed inverted open reading 

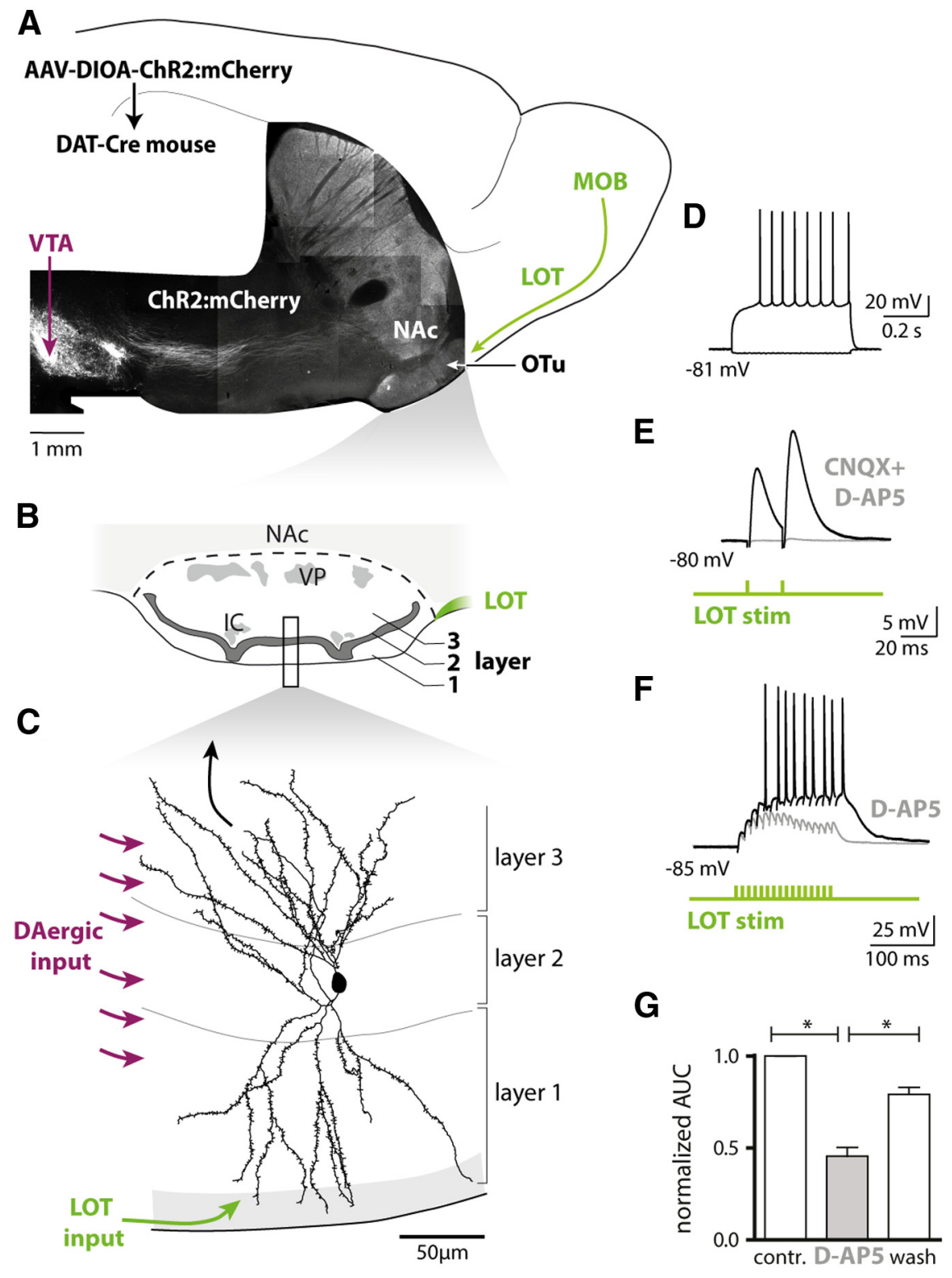

Figure 1. Glutamatergic inputs from the olfactory bulb excite layer 2 SPNs. A, Sagittal view of the mouse forebrain showing the location of the OTu in the ventral striatum with ChR2:mCherry expression after injection of AAVV $_{1 / 2}$-DIOA-Chr2:mCherry in the ventral midbrain of DAT-Cre mice. DAergic midbrain projections terminate at high density in all layers of the OTu. The LOT fiber tract in the superficial parts of layer 1 terminate on layer 2 SPNs that in turn project to other brain regions. NAc, Nucleus accumbens; MOB, main olfactory bulb; VTA, ventral tegmental area; IC, Islands of Calleja; VP, ventral pallidum. $\boldsymbol{B}$, Coronal view of the OTu. $\boldsymbol{C}, \boldsymbol{D}$, Reconstruction of a biocytin-filled SPN in layer 2 ( $C$ ) and its firing response to a 1 s current step injection (current steps: $-50,+400$ PA; $\boldsymbol{D})$. $\boldsymbol{E}$, Short-latency evoked EPSPs in an SPN evoked by electrical stimulation of the LOT were blocked by NMDAR/AMPAR antagonists D-AP5 (50 $\mu \mathrm{m})$ and CNQX (10 $\mu \mathrm{m} ; V_{\mathrm{m}}$ is indicated in this and subsequent figures). $\boldsymbol{F}$, Short stimulation of LOT for $150 \mathrm{~ms}$ at $100 \mathrm{~Hz}$ drove the membrane potential of an SPN to the firing threshold. AP firing was blocked by the NMDAR antagonist D-AP5 $(50 \mu \mathrm{M})$. G, The area under the membrane potential curve (AUC) during $100 \mathrm{~Hz}$ LOT stimulation in $\boldsymbol{F}$ was normalized to the control condition for statistical analysis [ $p<0.05$, ANOVA with post-test $\left.\left({ }^{*} p<0.05\right), n=5\right]$.

frame (DIOA) containing ChR2 fused to mCherry ( $\mathrm{rAAV}_{1 / 2^{-}}$ DIOA-ChR2:mCherry) into the ventral midbrain of 8 -week-old DAT-Cre mice. On average, 3 weeks after injection, half of tyrosine hydroxylase ${ }^{+}$neurons expressed ChR2:mCherry in the ventral midbrain (Wieland et al., 2014) with dense ChR2: $\mathrm{mCherry}^{+}$projections in the OTu (Fig. 1A). PLS 5 ms laser pulses at $40 \mathrm{~Hz}$ of ChR2:mCherry ${ }^{+}$afferents evoked transient peaks of DA release in layer 2 of the adult OTu (Wieland et al., 2014).

We examined whether optogenetically evoked release from DAergic terminals would potentiate EPSPs and/or the evoked firing rate of SPNs. To examine changes in the output firing of SPNs, we periodically applied $100 \mathrm{~Hz}$ stimulation for $500 \mathrm{~ms}$ to the LOT every $20 \mathrm{~s}$ (hereafter named OSTIM; Fig. $2 A, B)$, mimicking the firing of olfactory bulb projection neurons during odor presentation. Repetition of an OSTIM every $20 \mathrm{~s}$ throughout the recording evoked stable AP responses for at least $40 \mathrm{~min}$ ( $p=$ n.s., ANOVA; $n=8$; Fig. $2 C$ ). In addition to OSTIM, paired pulses were applied to LOT to determine potential presynaptic and postsynaptic effects during plasticity; and a negative intracellular current was injected to monitor input resistance. AChRs were blocked with $\mathrm{DH} \beta \mathrm{E}$ $(2 \mu \mathrm{M})$ and atropine $(2 \mu \mathrm{M})$ to examine the direct actions of pDA on SPNs. In mice with expression of ChR2 in DAergic neurons $\left(\mathrm{ChR} 2^{+}\right)$, we first recorded a stable baseline during OSTIM and then paired the OSTIM 15 times with PLS. PLS had a delayed onset relative to an OSTIM of $100 \mathrm{~ms}$ (Fig. 2B) to account for delays of phasic bursting of DAergic neurons after the sensory stimulus onset (Ljungberg et al., 1992). After the pairing of OSTIM and PLS, we applied OSTIM alone for the remainder of the recording for at least 25 min to test for durability of the plasticity. We tested both for the potentiation of synaptic inputs and changes in the inputoutput function (IOF) of SPNs. The IOF was defined as the number of APs evoked by a constant OSTIM. Pairing OSTIM with the PLS resulted in a significant potentiation of the EPSP amplitude and increased the IOF (both $p<0.001$, ANOVA; $n=18$; Fig. $2 D, E)$. The potentiated EPSP amplitude and the IOF slowly returned to baseline levels within several minutes after the pairing with PLS had stopped. The PPR of EPSP did not change ( $p=$ n.s., ANOVA), suggesting that the site of potentiation is most likely at the postsynapse. We confirmed that without a pharmacological block of the AChRs, PLS still evoked potentiation of the EPSP amplitudes ( $144 \pm 10 \%$ of baseline) and increased the IOF $(167 \pm 12 \%$ of baseline; $n=6$ SPNs). Application of the same pairing of PLS and OSTIM in ChR2 ${ }^{-}$ mice (Fig. 2E) changed neither the EPSP amplitude nor the IOF. Thus, pDA both potentiated the EPSP and increased the IOF with a similar time course when paired to OSTIM. Interestingly, even though the potentiation of the EPSP amplitude and the change in the IOF were significant when all recorded SPNs were pooled (Fig. $2 E$ ), the IOF increased in only 10 of 18 SPNs in $\mathrm{ChR} 2{ }^{+}$mice above the variability observed in ChR2 ${ }^{-}$mice (Fig. $2 F$ ). The 10 SPNs with potentiated EPSP amplitude in $\mathrm{ChR}_{2}{ }^{+}$mice were also the ones with increased IOF (Fig. $2 F$ ). In the 10 SPNs with potentiation of EPSP amplitudes, PPR and input resistance normalized to baseline (pre) remained 
A
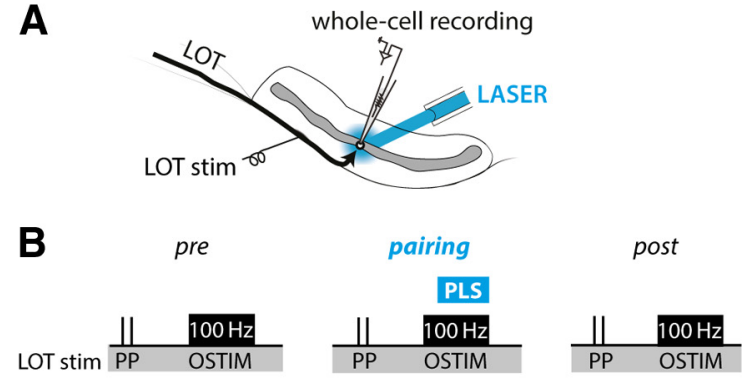

C

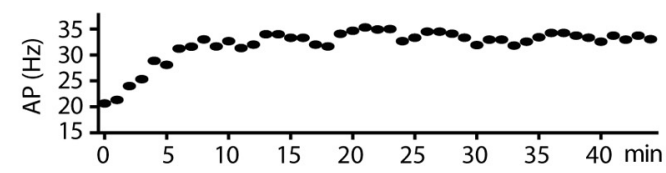

D

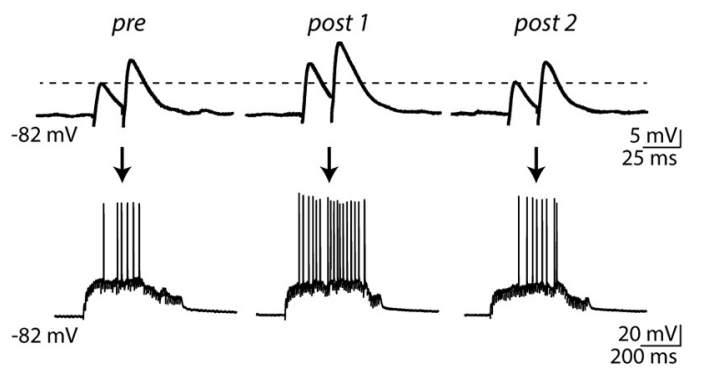

E
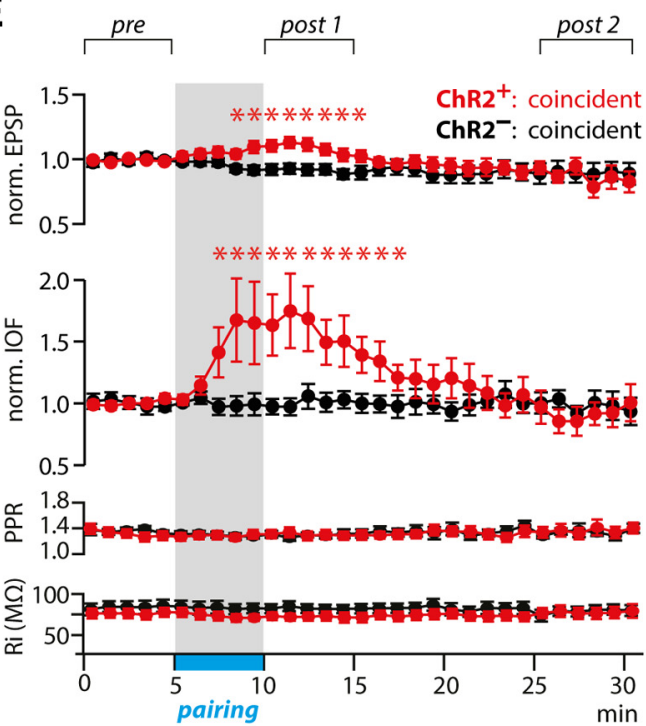

$\mathbf{F}$

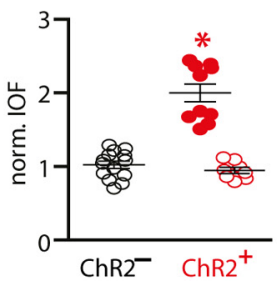

G

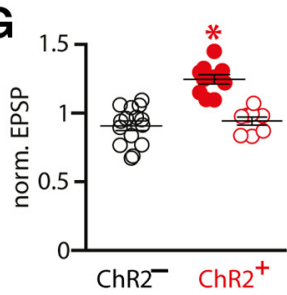

Figure 2. Phasic dopamine reversibly potentiates olfactory input and SPN output. $A$, Recording configuration. $B$, Experimental paradigm: paired-pulse LOT stimulation (PP, interstimulus interval, $20 \mathrm{~ms}$ ) and OSTIM $(100 \mathrm{~Hz}, 500 \mathrm{~ms})$ were alternating every 10 s throughout the experiment. After recording of a baseline, PLS ( $40 \mathrm{~Hz}, 400 \mathrm{~ms})$ was paired coincidentally with 0STIM (latency, $100 \mathrm{~ms}$ after onset of OSTIM). C, Continuous application of OSTIM every 20 s elicited stable AP firing after 5-10 min. D, Recordings from a SPN are shown pre, post 1, and 20 min after the pairing (post 2) in $\mathrm{a}_{\mathrm{ChR2}}{ }^{+}$mouse $\left(I_{\text {inj }}=0 \mathrm{pA}\right)$. Top row, EPSPs evoked by paired-pulse stimulation. Bottom row, AP firing in response to OSTIM. E, Effect of coincident PLS pairing on SPNs in ChR2 ${ }^{-}$mice $($black, $n=$ 14) and ChR2 ${ }^{+}$mice (red, $n=18$ ) over time. From top to bottom, Effect on normalized EPSP amplitude and, IOF (defined as the number of APs per OSTIM), paired-pulse ratio, and input resistance. Normalized EPSP amplitude and IOF: $p<0.001$, ANOVA with post-test $\left({ }^{*} p<0.05\right)$. $F$, Plot of the normalized EPSP amplitude and the normalized IOF in response to 0 OSTIM directly after the induction (post 1) for single cells (average of 5 min post 1 normalized to pre). Neurons were considered "potentiated" if their normalized EPSP increased more than the largest increase in ChR ${ }^{-}$controls. The same 10 "potentiated" cells also were the ones with the largest increases in normalized IOF (both * $p<0.05, t$ test).

unchanged during this period (post $1 ; 100.9 \pm 2.8 \%$ and $106.0 \pm$ $5.7 \%$, respectively; both $p=$ n.s., $t$ test). We therefore separated the cells in $\mathrm{ChR} 2{ }^{+}$mice into potentiated and nonpotentiated SPNs (Fig. 3) to examine whether the site of pDA-induced plasticity was confined to the stimulated synapse and whether homeostatic plasticity contributed significantly to the modification of dendritic integration or somatic excitability. The potentiation of the EPSP amplitude was positively correlated with AP spiking in potentiated SPNs but not in nonpotentiated SPNs (Fig. 3A). Similar correlations were found for the slope of the EPSP rising phase and AP spiking (Fig. $3 B$ ).

Dendritic integration may change during plasticity and result in the amplification of synaptic inputs. Voltage-gated conductances located in the dendrites can amplify EPSPs (Lipowsky et al., 1996; Hoffman et al., 1997; Magee, 1998). Changes in active dendritic propagation will affect the ratio of the EPSP amplitude to the slope of its rising phase (A/Slp ratio). Analysis of the pDAinduced plasticity revealed that the increases in the EPSP amplitude correlated positively with changes in the EPSP rising phase $\left(R^{2}=0.38, n=10\right)$. Consequently, the $\mathrm{A} / \mathrm{Sl}$ p ratio did not change in potentiated cells ( $p=$ n.s., ANOVA; $n=10$; Fig. $3 C$ ). In support of active dendrites in SPNs of the OTu, a potassium channel antagonist indeed increased the A/Slp ratio of EPSPs evoked by stimulation of the LOT in SPNs (Fig. 3D).
We finally tested for changes in the membrane potential threshold at which APs occurred during OSTIM-induced depolarization (Fig. $3 E$ ). Even though pDA increased the IOF, the threshold did not change in the first pairings of PLS and OSTIM (Fig. 3E). Also, the threshold did not change after pairing of the PLS with OSTIM was completed ( $p=$ n.s., ANOVA; $n=10$; Fig. $3 F)$, supporting that the increase in output firing was not due to a lowered firing threshold during the potentiation phase. A recent study (Planert et al., 2013) described that pharmacologic $D_{1} R$ activation changed the membrane threshold at which the first AP occurred during intracellular current ramp injections. We tested whether pDA release acutely modified the threshold for AP firing that was elicited via 2 s current ramps. Current ramps were adjusted so that the first AP occurred $1 \mathrm{~s}$ after ramp onset. PLS started either early (200 ms before ramp onset) or late ( $1 \mathrm{~s}$ after ramp onset). Neither early nor late PLS changed the membrane threshold at which the first AP occurred (early PLS, $V_{\mathrm{m}}=$ $-51.84 \pm 0.73 \mathrm{mV}$ vs alternating no-PLS, $-51.79 \pm 0.72 \mathrm{mV}$ in the same 18 cells; late PLS, $V_{\mathrm{m}}=-49.80 \pm 1.22 \mathrm{mV}$ vs alternating no-PLS, $-49.75 \pm 1.23 \mathrm{mV}$ in the same 13 cells; both $p=$ n.s., $t$ test). These results do, however, not exclude that other parameters of intrinsic excitability are acutely changed by endogenous pDA. Together, these findings support that increased firing output to the same sensory stimulus was due to synaptic potentiation 

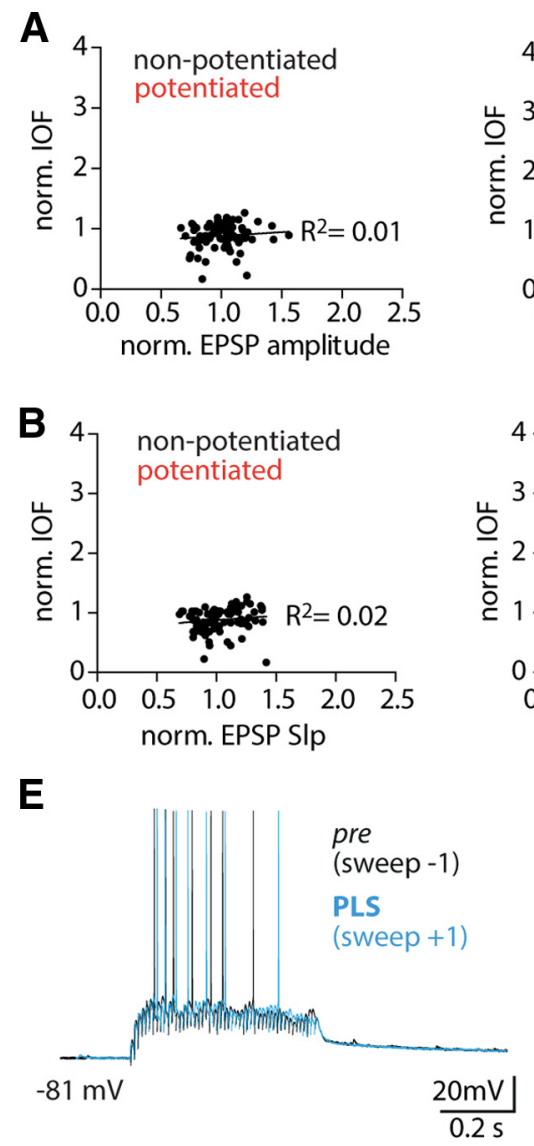
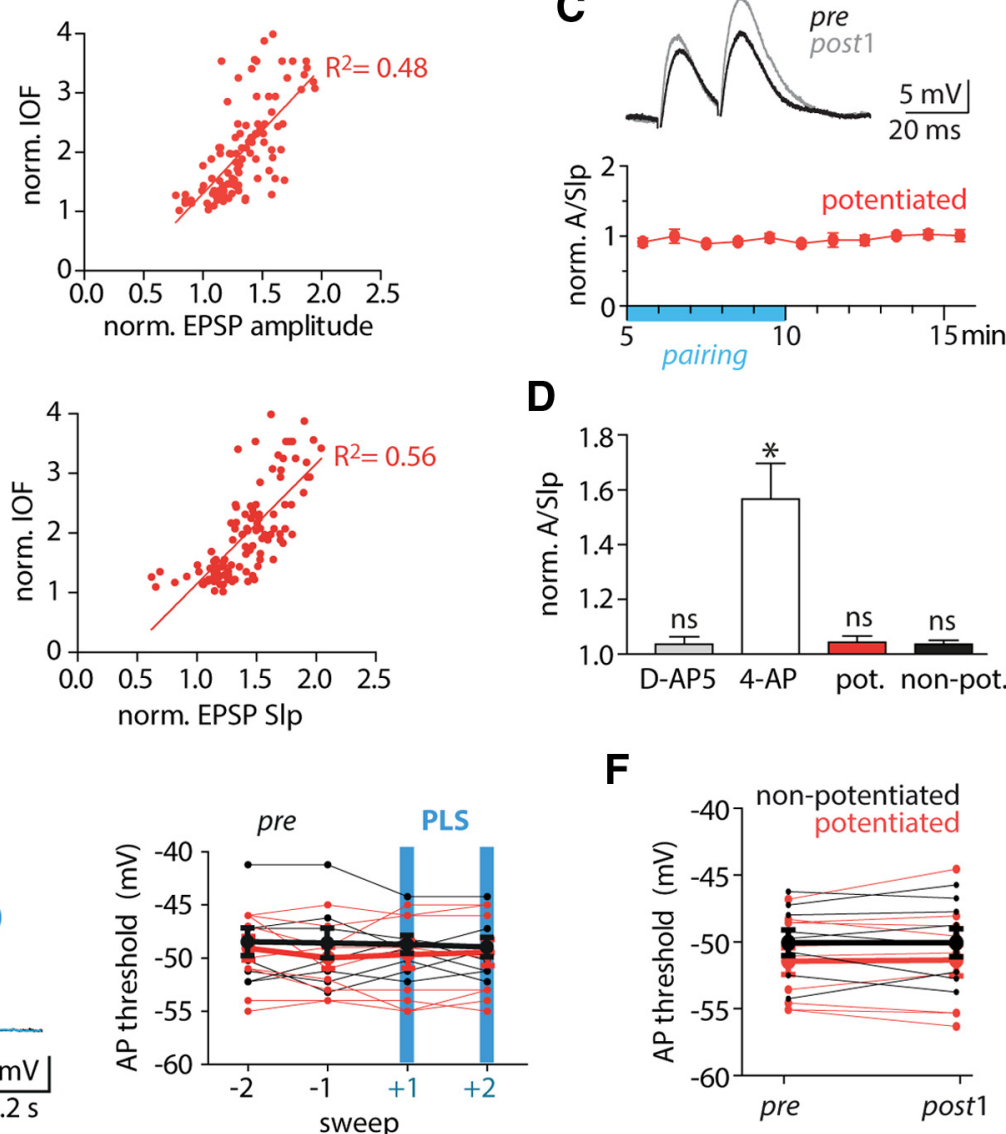

Figure 3. Phasic dopamine induces synaptic potentiation without homeostatic compensation. $\boldsymbol{A}, \boldsymbol{B}$, Relationship of the normalized IOF to the normalized EPSP amplitude $(\boldsymbol{A})$ or to the normalized slope of the EPSP rising phase (B) after pairing of pDA and OSTIM (post 1). Normalized values from single sweeps are plotted from measurements obtained during post 1 of nonpotentiated (black, $n=8$ ) and potentiated subset of cells (red, $n=10$ ) from ChR2 ${ }^{+}$mice. $C$, The A/SIp ratio was normalized to that before induction. The normalized A/SIp ratio baseline did not change in the 10 potentiated cells over time. D. The effect of drugs (50 $\mu \mathrm{m}$ D-AP5 and $1 \mathrm{~mm} 4-\mathrm{AP}$ ), and the pairing of PLS and 0STIM were tested for the A/SIp ratio normalized to the baseline before the manipulation ( $n=4,9,10$, and 8 cells, respectively). ${ }^{*} p<0.05, t$ test. $\boldsymbol{E}$, Whole-cell current-clamp recordings of the cumulative discharge during $0 S T I M\left(I_{\text {inj }}=0 \mathrm{pA}\right)$ before and during the coincident pairing of PLS and OSTIM. Plot of the membrane potential threshold at which the first AP occurred during OSTIM for the first coincident OSTIM-PLS pairing \pm 2 sweeps. $\boldsymbol{F}$, Before the first coincident OSTIM-PLS induction (pre) and after the pairing (post 1), the membrane potential at which the first AP occurred was measured for the 10 potentiated (red) and 8 nonpotentiated cells (black).

without a downregulation of dendritic integration or a change in the somatic firing threshold.

\section{Phasic DA-induced plasticity depends on timing and input frequency}

Next, we examined whether pDA signals would still potentiate olfactory inputs if the DA signal begins $1 \mathrm{~s}$ before or $1 \mathrm{~s}$ after OSTIM (Fig. 4A, B). We observed that EPSPs and the IOF did not potentiate significantly when PLS started $1 \mathrm{~s}$ before OSTIM onset (both $p=$ n.s., ANOVA; $n=10$ SPNs; Fig. 4E,F). Similarly, EPSPs and the IOF did not change when the PLS was applied $1 \mathrm{~s}$ after the OSTIM (both $p=$ n.s., ANOVA; $n=10$ SPNs; Fig. $4 E, F)$. Thus, pDA acting on olfactory inputs required precise timing for the induction of plasticity in adult SPNs.

We also tested for information selectivity of the observed plasticity. Olfactory bulb projection neurons regularly fire bursts of up to $20 \mathrm{~Hz}$ in the absence of an odor in contrast to $100 \mathrm{~Hz}$ during odor responses. We mimicked these background inputs by $20 \mathrm{~Hz}$ stimulation to the LOT for $500 \mathrm{~ms}$ every $20 \mathrm{~s}$ (BSTIM). Thus, in this paradigm, we kept all stimulation parameters constant except that we switched from $100 \mathrm{~Hz}$ (OSTIM) to $20 \mathrm{~Hz}$ (BSTIM) during pairing with the PLS (Fig. 4C). Neither the EPSP amplitude nor the IOF were significantly potentiated (both $p=$ n.s.,
ANOVA; $n=17$; Fig. $4 E, F)$. Notably, BSTIM in contrast to OSTIM did not elicit APs at the same stimulation intensity. These observations suggest that pDA selectively potentiates coincident olfactory inputs over background inputs in a frequency-dependent manner.

\section{Phasic DA-induced plasticity is mediated by $D_{1}$ Rs expressed in a subset of SPNs}

Even though the potentiation of the EPSP amplitudes and the increase in the IOF was significant when all recorded SPNs were pooled (Fig. 2), pDA only induced increases in the synaptic amplitudes and firing output in a subset of SPNs. This heterogeneity raised the possibility that the observed plasticity required the activation of $\mathrm{D}_{1}$ Rs. In the dorsal striatum, $\mathrm{D}_{1}$ Rs are only expressed in a subset of SPNs (Surmeier et al., 1996). Phasic DA release evokes peaks of extracellular [DA] that can activate low-affinity $\mathrm{D}_{1}$ Rs. We tested whether the potentiation of EPSPs and the increase in the IOF upon the pairing of PLS and OSTIM was blocked by the $\mathrm{D}_{1} \mathrm{R}$ antagonist SCH23390 (10 $\mu \mathrm{M}$; Fig. $4 D$ ). Indeed, the $\mathrm{D}_{1} \mathrm{R}$ antagonist prevented potentiation of the EPSP amplitude and increase in the IOF (both $p=$ n.s., ANOVA; $n=11$ SPNs; Fig. $4 E, F$ ). Together these findings reveal that the pDA-induced potentiation of EPSPs and firing output requires $\mathrm{D}_{1} \mathrm{R}$ activation. 


\section{A PLS before OSTIM}

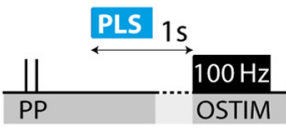

B PLS after OSTIM

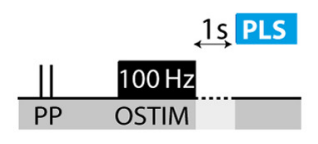

C background

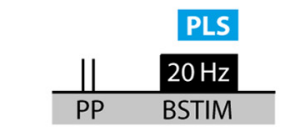

D
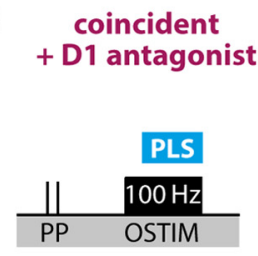

$$
\text { pre } \rightarrow \text { pairing } \rightarrow \text { post } 1
$$

\section{$\mathbf{E}$}
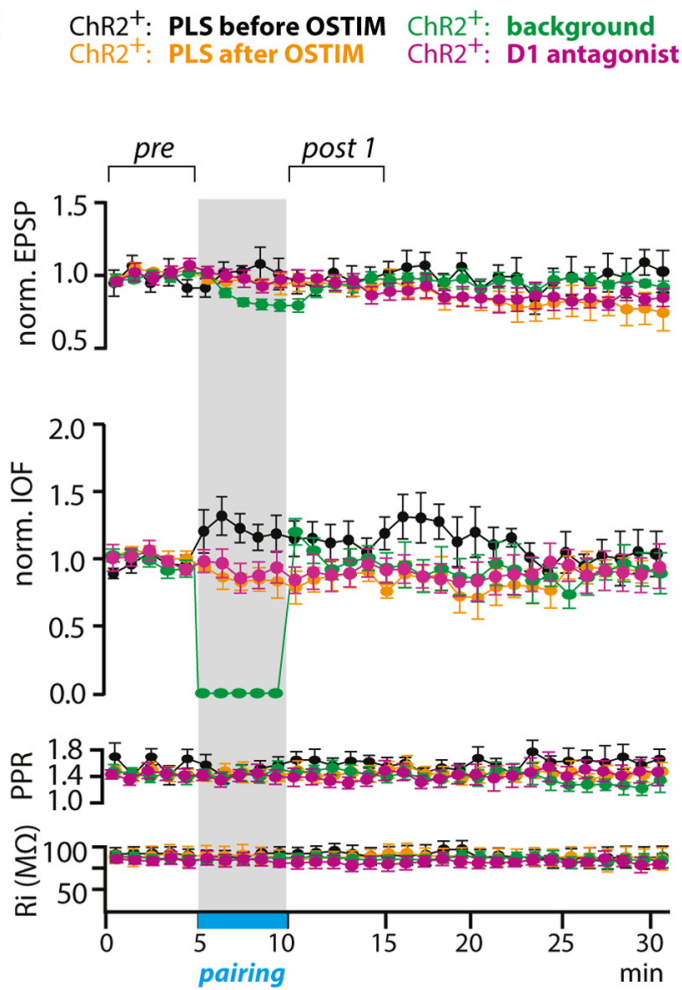

$\mathbf{F}$

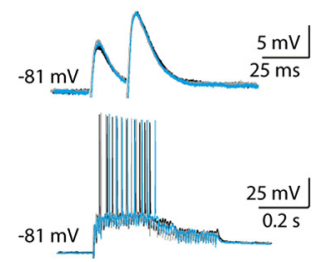

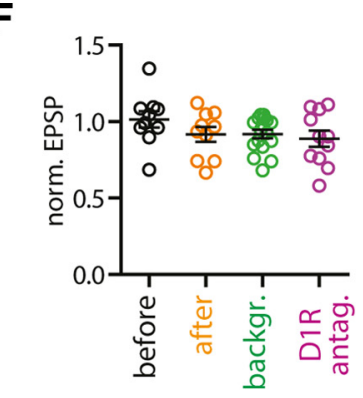

Figure 4. Features of phasic dopamine-induced plasticity. $\boldsymbol{A}-\boldsymbol{D}$, Left, Schemes of the pairing protocols. Right, Example traces of EPSPs evoked by paired-pulse stimulation (PP, top row) and AP firing in response to LOT stimulation in ChR2 ${ }^{+}$mice at $I_{\text {inj }}=0 \mathrm{pA}$. $\boldsymbol{A}$, Noncoincident pairing: PLS started $1 \mathrm{~s}$ before the start of the respective 0 STIM. $\boldsymbol{B}$, Noncoincident pairing: PLS started $1 \mathrm{~s}$ after the end of the respective OSTIM. C, BSTIM reflects output frequencies of olfactory bulb projection neurons at their baseline firing. During induction, the $100 \mathrm{~Hz}$ OSTIM was replaced by the $20 \mathrm{~Hz}$ BSTIM

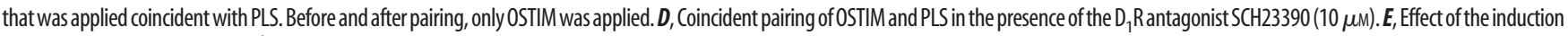
conditions shown in $\boldsymbol{A}-\boldsymbol{D}$ in ChR2 ${ }^{+}$mice $(n=10,10,17$, and 11, respectively) over time. From top to bottom, Effect on normalized EPSP amplitude, IOF, paired-pulse ratio, and input resistance (for all data, $p=$ n.S., ANOVA). Note that there was a transient overshoot in AP firing without an overshoot in EPSP amplitudes when switching from BSTIM to OSTIM that was also observed without PLS (data not shown). Also, the normalized IOF of the pairing PLS 1 s before OSTIM showed a tendency to increase, albeit this effect was not significant in our dataset ( $p=$ n.S., ANOVA).F, Plot of the normalized EPSP amplitude (left) and the normalized IOF (right) in response to OSTIM directly after the induction (post 1) for single cells (average of 5 min post 1 normalized to pre; all $p=$ n.s., $t$ test).

We had observed that $\mathrm{D}_{1} \mathrm{R}$-dependent potentiation only occurred in a subset of SPNs. This heterogeneity could be due to the dichotomous expression of $\mathrm{D}_{1}$ Rs and $\mathrm{D}_{2}$ Rs in SPNs of the OTu. We therefore crossed D1-dTomato and D2-GFP mice $(n=3)$, and observed that in layer 2 of the OTu, 305 of 607 cells only expressed dTomato and 302 only expressed GFP, but the two fluorescent proteins did not overlap in our sample (Fig. 5A). This segregation was similar to the dorsal striatum in the same mice, where 427 cells expressed only dTomato, 377 expressed only GFP, and 7 colocalized for both fluorescent proteins. Single-cell PCR from layer 2 cells revealed that most D1-dTomato ${ }^{+}$cells coexpressed $\mathrm{D}_{1} \mathrm{R}$ and Substance $\mathrm{P}$, while D1-dTomato ${ }^{-}$cells instead expressed $\mathrm{D}_{2} \mathrm{R}$ and enkephalin (Fig. $5 B, C$ ). These experiments, however, do not exclude the possibility that low coexpression of the other DARs exists. Together, we observed a dichotomy in the OTu that was similar to the one in the dorsal striatum (Fig. 5D).
We then addressed whether optogenetically evoked pDA release during OSTIM will induce synaptic plasticity in the majority of D1-dTomato ${ }^{+}$SPNs, and, importantly, whether the synaptic potentiation persists if OSTIM is removed directly after pairing (Fig. 6A). To first address this question, OSTIM was presented only during induction. OSTIM was paired with PLS in mice expressing ChR2 in DAergic neurons. Indeed, synaptic potentiation was observed for LOT inputs directly after pairing with OSTIM, but not in the control pathway (Fig. $6 B, C$ ). Synaptic potentiation of LOT inputs persisted for at least $25 \mathrm{~min}$ (averaged normalized EPSP amplitude for 30-35 min in Fig. $6 C$ (LOT, $1.43 \pm 0.23$; $p<$ $0.05, t$ test). We then confirmed the optogenetic effects on synaptic plasticity by application of the $\mathrm{D}_{1} \mathrm{R}$ agonist SKF38393 (10 $\mu \mathrm{M})$. The $\mathrm{D}_{1} \mathrm{R}$ agonist itself did not change the EPSP amplitude and PPR (Fig. $6 D, E$ ), compatible with lack of $\mathrm{D}_{1}$ Rs in olfactory bulb projection neurons (Mansour et al., 1990). We then applied OSTIM in presence of the $\mathrm{D}_{1} \mathrm{R}$ agonist (Fig. $6 F, G$ ). Before and 
A

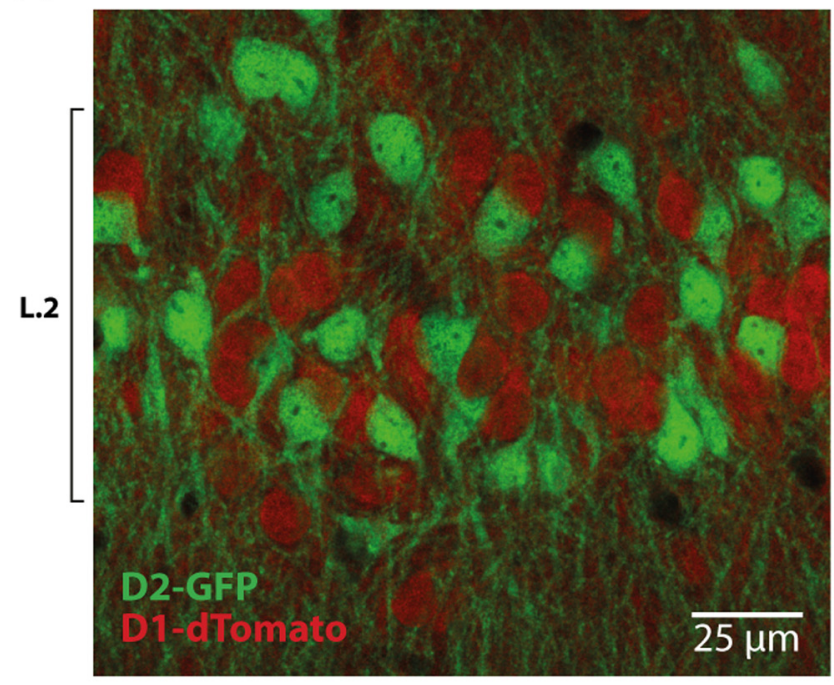

B

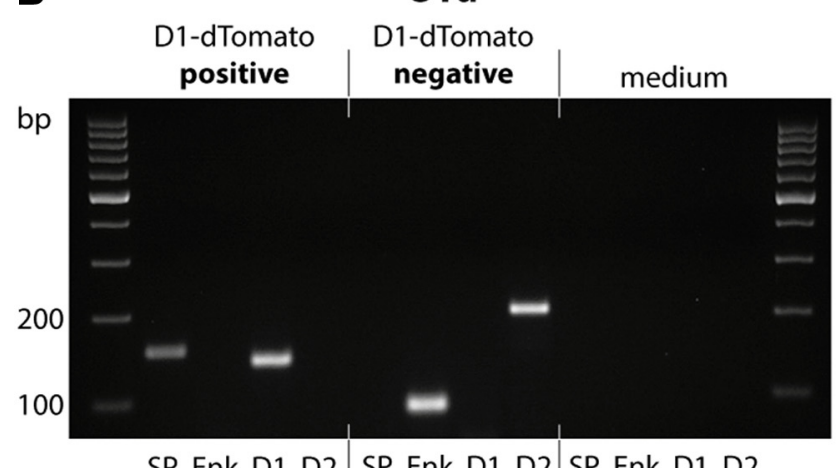

SP Enk D1 D2 $\mid$ SP Enk D1 D2 $\mid$ SP Enk D1 D2

C

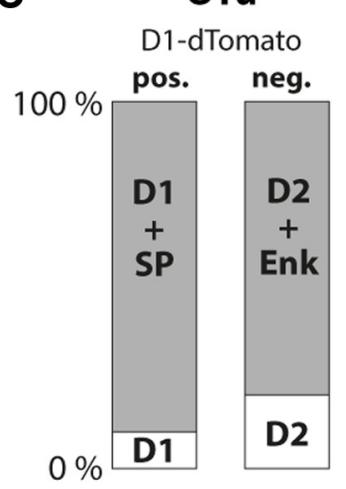

D

D dors. Str.

D1-dTomato

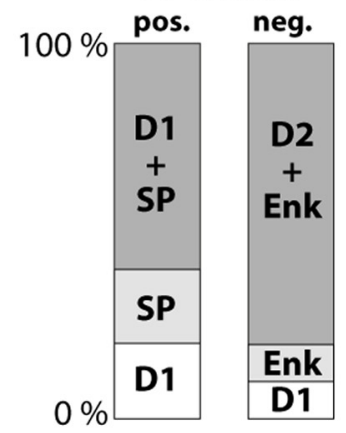

Figure 5. Molecular segregation of $D_{1} R$ and $D_{2} R$ SPNs. $A$, Segregation of dTomato ${ }^{+}$and $\mathrm{GFP}^{+}$neurons in layer 2 of the OTu of double D1-dTomato and D2-GFP reporter mice. $\boldsymbol{B}$, Example of a single-cell PCR from a D1-dTomato ${ }^{+}$and a D1-dTomato ${ }^{-}$cell of the OTu and coexpression of Substance $P\left(S P, 153\right.$ bp), enkephalin (Enk; 91 bp), $D_{1} R\left(D_{1}, 140\right.$ bp), $D_{2} R\left(D_{2}\right.$, $205 \mathrm{bp}$ ). The right lanes originate from aspiration of medium without a cell. $C, D$, Fraction of cells coexpressing $D_{1} R, D_{2} R$, Substance $P(S P)$, and enkephalin derived from single-cell $P C R$ of 13 D1-dTomato ${ }^{+}$and 13 D1-dTomato ${ }^{-}$cells of layer 2 of the OTu $(C)$ and of 10 D1-dTomato ${ }^{+}$ and 10 D1-dTomato ${ }^{-}$cells in the dorsal striatum (dors. Str.; D). pos., Positive; neg., negative.

after OSTIM we evoked single EPSPs through LOT stimulation. In wild-type mice, only part of SPNs displayed a $D_{1} R$ agonistinduced synaptic potentiation directly following OSTIM $(p<$ $0.05, t$ test; Fig. $6 G$ ) that persisted for at least $25 \mathrm{~min}$ (averaged

normalized EPSP amplitude for 30-35 min in Fig. 6G, $2.22 \pm$ $0.43 ; p<0.05, t$ test). In the absence of the $\mathrm{D}_{1} \mathrm{R}$ agonist, no synaptic potentiation was induced by OSTIM ( $p=$ n.s., $t$ test; Fig. $6 G)$. Importantly, in D1-dTomato marker mice, OSTIM in the presence of the $D_{1} R$ agonist resulted in potentiation of the synaptic input in most recorded D1-dTomato ${ }^{+}$SPNs directly following OSTIM ( $p<0.05, t$ test; Fig. $6 H, I)$ that persisted for at least $25 \mathrm{~min}$ (averaged normalized EPSP amplitude for 30-35 $\min , 2.33 \pm 0.42 ; p<0.05, t$ test; Fig. $6 I$ ). Furthermore, the potentiation was observed only in the OSTIM-activated inputs (superficial part of layer 1), but not in the control pathway (layer 3 ), revealing input specificity of the synaptic plasticity. In the potentiated pathway, PPR (Fig. 6I) and the A/Slp ratio of the EPSP $(107.2 \pm 11.9 \%$ of the respective control value) remained unchanged (both $p=$ n.s., $t$ test), revealing that presynaptic release and dendritic integration did not significantly contribute to the synaptic potentiation, as has already been observed for pDAinduced plasticity. In the above experiments, stimulation intensity had been adjusted so that each OSTIM evoked more than three APs. We also tested whether AP firing during OSTIM was required to induce synaptic potentiation. The EPSP amplitude was not potentiated in D1-dTomato ${ }^{+}$SPNs in which OSTIM elicited only one or no APs in the presence of the $D_{1} R$ agonist (Fig. 6I). This further supports the idea that the induction of $\mathrm{D}_{1} \mathrm{R}$-dependent synaptic plasticity requires robust postsynaptic spiking during induction. Finally, we confirmed that intrinsic excitability remained unchanged. In four SPNs that underwent synaptic potentiation (averaged normalized EPSP amplitude for $30-35 \mathrm{~min}, 2.51 \pm 0.41 ; p<0.05$, $t$ test), we had injected current steps before and again $25 \mathrm{~min}$ after plasticity induction. The threshold and rheobase of the first AP did not change in response to increasing current steps before and after the plasticity induction (AP threshold: pre, $V_{\mathrm{m}}=-46.8 \pm 1.5 \mathrm{mV}$ vs post, $V_{\mathrm{m}}=$ $-48.8 \pm 1.2 \mathrm{mV}$; rheobase: pre, $194.4 \pm 45.3 \mathrm{pA}$ vs post, $247.5 \pm$ $67.8 \mathrm{pA}$; both $p=$ n.s., $t$ test). In summary, these experiments support that the DA-induced synaptic potentiation was input specific and confined to $\mathrm{D}_{1} \mathrm{R}$-expressing SPNs (Fig. 7).

\section{Discussion}

In this study, we examined cellular plasticity by which a salience signal of dopaminergic midbrain neurons modifies sensory inputs in a striatal circuit. Evoked endogenous pDA release induced reversible synaptic potentiation of temporally correlated sensory inputs through the activation of $\mathrm{D}_{1}$ Rs that are expressed in a subset of SPNs. This form of pDA-induced plasticity has properties to function as a cellular mechanism for dynamic top-down selection of relevant stimuli.

Phasic increases in DA concentration are particularly well suited to activate low-affinity $\mathrm{D}_{1}$ Rs in SPNs (Dreyer et al., 2010). Indeed, we observed that synaptic potentiation induced by evoked $\mathrm{pDA}$ release required $\mathrm{D}_{1} \mathrm{R}$ activation and was observed only in a subset of SPNs in the OTu. Similarly, synaptic plasticity induced by a $\mathrm{D}_{1} \mathrm{R}$ agonist was observed in a subset of SPNs that express $D_{1}$ Rs. SPNs in the OTu segregated into subsets of SPNs that are Substance $\mathrm{P}^{+} / \mathrm{D}_{1} \mathrm{R}^{+}$or enkephalin ${ }^{+} / \mathrm{D}_{2} \mathrm{R}^{+}$like in the dorsal striatum. Thus, the observed pDA-induced plasticity was confined to a subset of molecularly defined SPNs.

The ventral striatum is involved in the assignment of value to stimuli (Berridge and Robinson, 1998; Kapur, 2003; BrombergMartin et al., 2010). A number of features may be predicted for pDA-induced plasticity of sensory coding if it plays a role in the selection of relevant stimuli. The first prediction is that the relatively short duration of pDA concentration peaks (lasting a few 
A

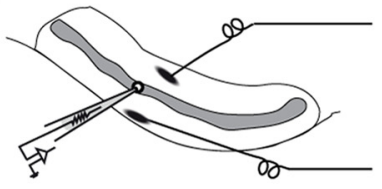

L.3 stimulation (control pathway)

LOT stimulation (OSTIM)

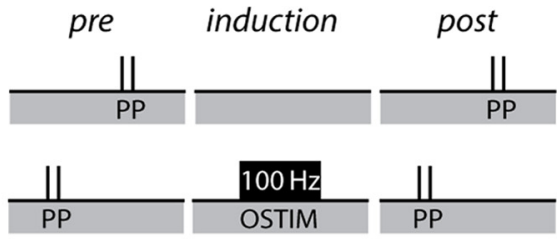

B

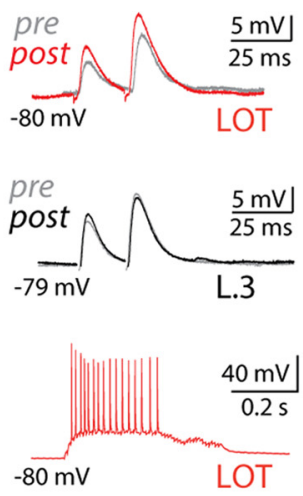

D

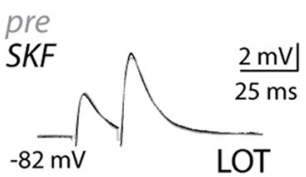

F
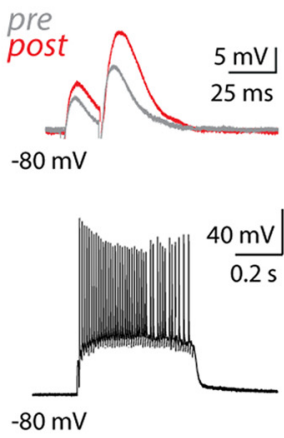

H high (H)
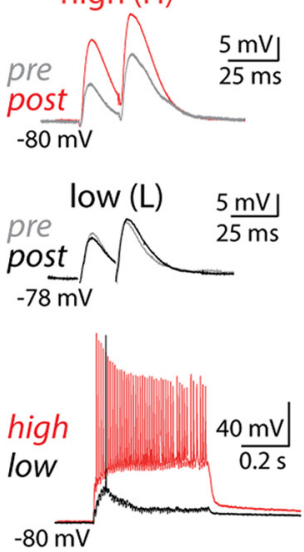

C

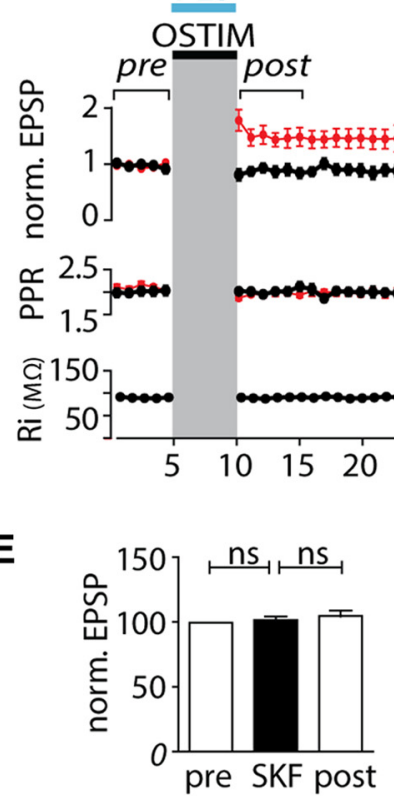

G

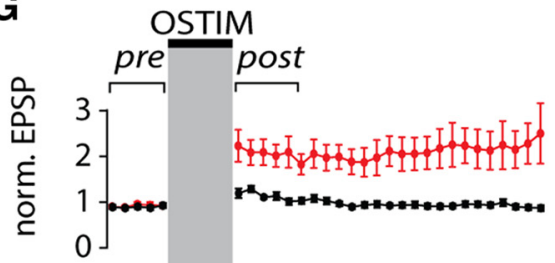

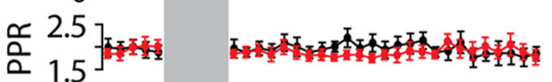

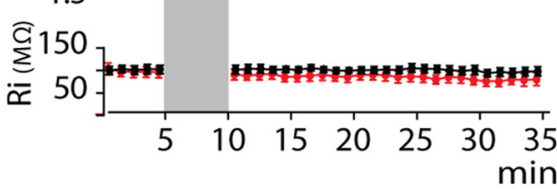

I

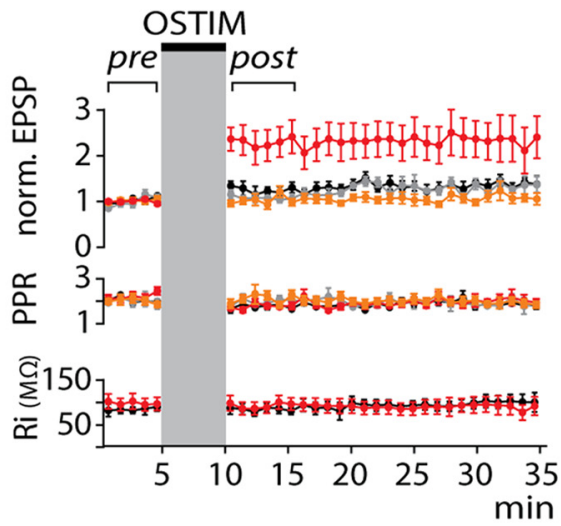

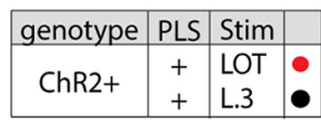
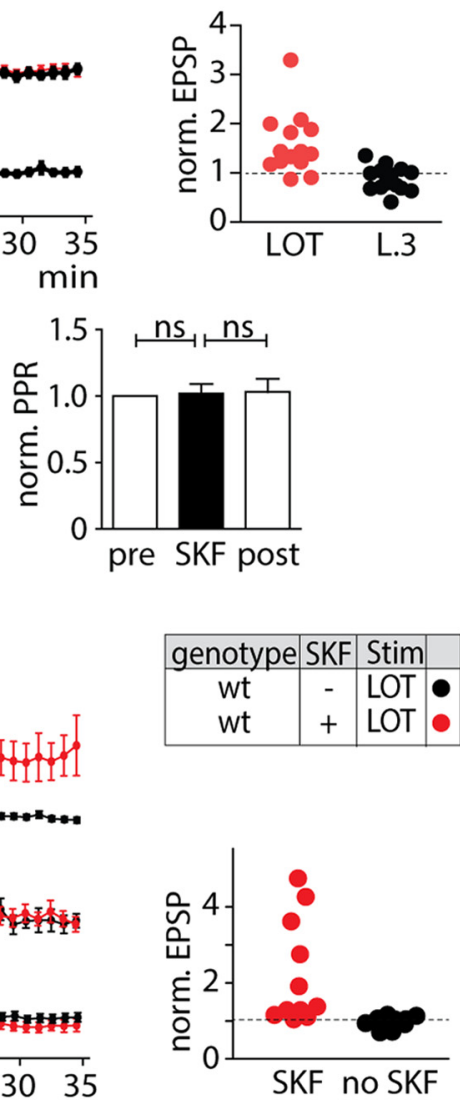
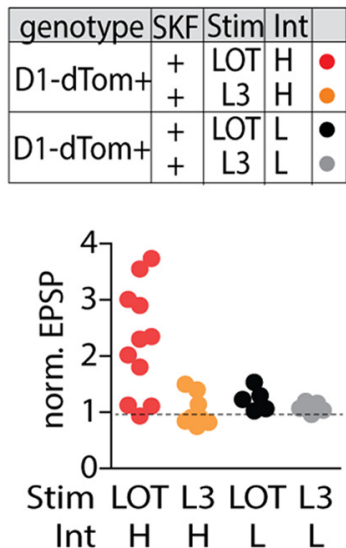

Figure 6. The pairing of OSTIM and $D_{1} R$ activation induces synaptic potentiation in $D_{1}$ SPNs. $A$, Schematic configuration of the two stimulation paradigms: after application of paired-pulse stimulation (PP, interstimulus interval, $20 \mathrm{~ms}$ ) for at least $5 \mathrm{~min}$, OSTIM was applied 15 times in the LOT, whereas in the control pathway (L.3 stim) no 0STIM was applied. After induction, paired pulses were continuously monitored in both paradigms. B, C, Effect of PLS and OSTIM pairing during induction. B, Example traces of EPSPs evoked by LOT (Figure legend continues.) 


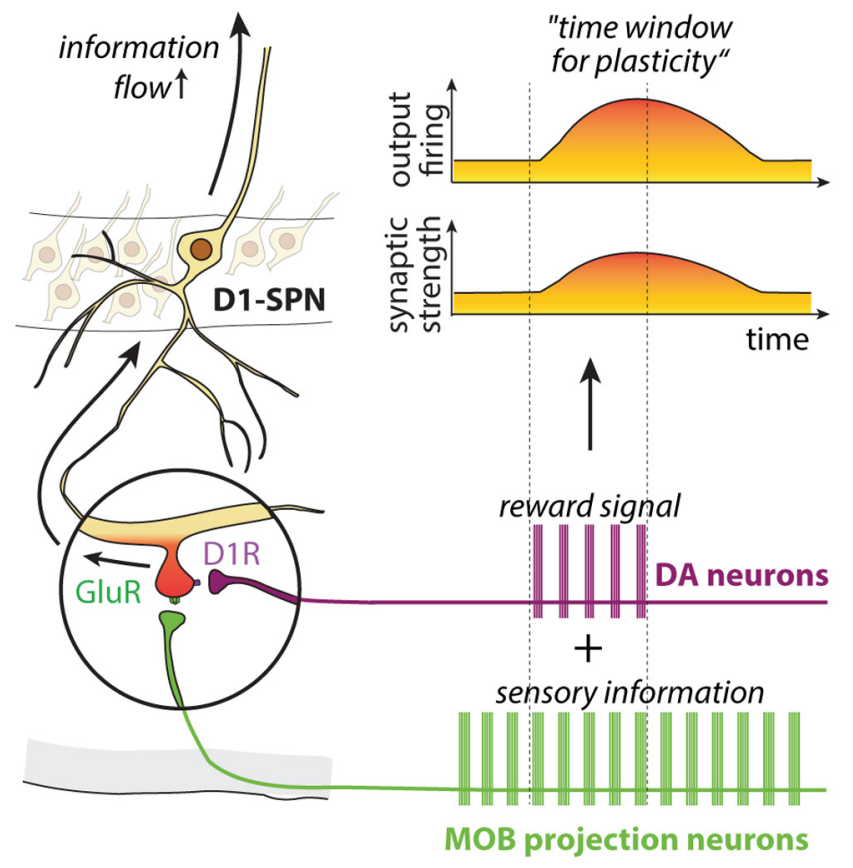

Figure 7. The scheme summarizes the dynamics and mechanisms through which phasic dopamine release induces an increase in the output rate to a constant olfactory input through synaptic plasticity.

seconds) may serve to provide a timestamp on glutamatergic inputs to striatum (Kapur, 2003; Redgrave and Gurney, 2006), strengthening those striatal input-output connections that are active at the time of the reward-associated event. The timestamp is thus influenced by two factors, the kinetics of pDA release and of DAR activation as $\mathrm{D}_{1}$ Rs that are metabotropic receptors and act on timescales of hundreds of milliseconds (Kreitzer, 2009). We observed a narrow time window for the induction of $\mathrm{pDA}$ induced synaptic plasticity that spanned less than $\pm 1 \mathrm{~s}$ between OSTIM and pDA. Similarly, pDA-induced spine enlargement was observed only if pDA occurred within $<1$ s before or after the excitation of SPNs (compare Fig. 1 N, O in Yagishita et al., 2014). It is, however, possible that different time windows and rules exist for other forms of plasticity (Abbott and Nelson, 2000). Interestingly, in striatal cholinergic interneurons pDA also elicited $\mathrm{D}_{1^{-}}$

$\leftarrow$

(Figure legend continued.) stimulation (top row) and L.3 stimulation (middle row). AP firing during 0STIM (bottom row) in $\mathrm{ChR}^{+}{ }^{+}$mice at $l_{\text {inj }}=0 \mathrm{pA}$. C, Average data from 14 SPNs in $\mathrm{ChR2}^{+}$mice revealed a potentiation of the EPSP amplitude only for LOT stimulation in which OSTIM was applied during PLS. From top to bottom, Effect on normalized EPSP amplitude, paired-pulse ratio, and input resistance. Lower right, Scatter plot of the normalized EPSP amplitudes (post over pre). Each dot represents a cell. D, E, Application of the $D_{1}$ R agonist SKF38393 $(10 \mu \mathrm{M})$ did not change the EPSP amplitude or PPR when paired pulses were evoked alone in the LOT of wild-type mice (all $p=$ n.S., ANOVA; $n=8$ ). $\boldsymbol{F}, \mathbf{G}$, Effect of $D_{1} R$ activation on LOT stimulation in wild-type mice. $F$, Example traces of EPSPs (top row) in the presence of the $D_{1} R$ agonist SKF38393 $(10 \mu \mathrm{M}$ ), and AP firing (bottom row) during 0STIM. G, Average data from SPNs revealed a potentiation of the EPSP amplitude $(n=11)$ in the presence of SKF38393 (10 $\mu \mathrm{M})$, but not in the absence of the agonist $(n=10)$. Lower right, Scatter plot of the normalized EPSP amplitudes. $\boldsymbol{H}, \boldsymbol{I}, \mathrm{D}_{1} R$ activation-induced potentiation requires AP firing during OSTIM in D1-dTomato ${ }^{+}$mice. $\boldsymbol{H}$, Example traces of EPSPs evoked by LOT stimulation for high-intensity (top row) or low-intensity induction (middle row). Membrane potential responses (bottom row) during high-intensity or low-intensity $0 S T I M$ at $I_{\text {inj }}=0 \mathrm{pA}$. I, Average data from D1dTomato ${ }^{+}$SPNs in the presence of the $D_{1} R$-agonist SKF38393 $(10 \mu \mathrm{M})$ with either highintensity ( $n=11$ ) or low-intensity ( $n=5$ ) 0STIM. Lower right, Scatter plot of the normalized EPSP amplitudes. type DAR-dependent firing responses that had terminated within $1 \mathrm{~s}$ (Wieland et al., 2014). In line with the preferential stamping of sensory inputs by a temporally nearby top-down signal, pDA potentiated olfactory inputs when the pDA began $100 \mathrm{~ms}$ after the onset of the sensory input, but not when the sensory input had stopped before the pDA began. Together, phasic burst responses of midbrain DA projections produce peaks of released DA and induce synaptic plasticity in currently active striatal input synapses.

The second prediction for value assignment is that the underlying mechanisms are dynamic as environmental stimuli may be relevant only for a period of time. We therefore established a protocol to determine the transient influence of pDA on the firing response to a constant sensory input. We observed that synaptic potentiation was slowly reversible when the input was no longer paired with a pDA signal. The molecular mechanisms underlying the reversibility of plasticity may be addressed in future studies. The focus of the present study was to understand the cellular processes underlying the plasticity of the input-output function of SPNs that are central to the third prediction.

The third prediction for plasticity induced by pDA is the preferential amplification of sensory information over background neuronal activity of glutamatergic inputs. In the olfactory bulb, projection neurons have output frequencies of $20 \mathrm{~Hz}$ at baseline and up to $\sim 100 \mathrm{~Hz}$ during odor responses (Shusterman et al., 2011). Downstream in the OTu, SPNs have very low firing frequency $(<2 \mathrm{~Hz})$ at baseline that increases up to $20 \mathrm{~Hz}$ or higher in response to odors (Wesson and Wilson, 2010). Thus, rate coding of odors is observed in both the olfactory bulb and the striatum. We mimicked these low-frequency background and highfrequency odor response outputs from the olfactory bulb. Highinput frequencies evoked cumulative AP discharges that were necessary to induce synaptic plasticity of AMPAR-mediated EPSPs when paired to pDA. Notably, synaptic plasticity in our study was induced without postsynaptic current injection. The block of NMDARs prevented postsynaptic EPSP summation to induce AP firing that was required to induce synaptic potentiation. NMDARdependent LTP induction was also found in the dorsal and ventral striatum (Reynolds et al., 2001; Shen et al., 2008; Cahill et al., 2014). NMDARs not only play a role in the induction of plasticity, they also can be potentiated in SPNs of the ventral striatum through $D_{1} R$ activation (Cahill et al., 2014). Our pDA-induced synaptic potentiation was selective to the stimulated sensory inputs. Considering that potentiation was preferentially observed at high-input frequencies upon odor presentation, it is possible that in the OTu, SPNs function as a high-pass filter and pDA is capable of increasing the gain of the rate code of the relevant odors.

Phasic DA induced a synaptic potentiation of the stimulated sensory inputs, but no changes were detected in the dendritic integration or somatic excitability, even though SPNs have dendrites with voltage-sensitive ion channels that influence the propagation of EPSPs as revealed by the blocking of $\mathrm{K}^{+}$conductances. The modulation of intrinsic conductances leading to dendrite- or cell-wide downregulation of excitability has been observed with different induction protocols and in certain neuron types (Debanne and Poo, 2010). In the original descriptions of homosynaptic plasticity, however, potentiation induced by highfrequency presynaptic stimulation is associated with enhanced firing probability of the postsynaptic neurons in response to excitatory input (Bliss and Lomo, 1973; Andersen et al., 1980). Similarly in SPNs of the OTu, pDA-induced synaptic potentiation left somatic and dendritic excitability untouched, thereby resulting in enhanced action potential firing output to the same input stimulus. Such a cellular plasticity mechanism would allow 
for differential amplification of sensory inputs with altered rate information transfer to downstream brain areas.

In summary, the pDA-induced plasticity examined in this study is compatible with models (Koechlin and Burnod, 1996; Redgrave and Gurney, 2006) proposing that signal attributes such as odor identity are encoded by activity within a population of neurons, while the salience of a sensory input is coded by the overall intensity of firing within the population. These features may provide correlates of cognitive processes in which certain stimuli become dominant over concurring inputs. DA has also been associated with aberrant salience. Aberrant salience describes a process in which associations of certain stimuli are formed too easily with other stimuli or associations, once formed, are not easily reversible (Kapur, 2003). Such aberrant salience of sensory inputs can result in delusions and may involve the cellular mechanisms by which DA induces plasticity to reversibly assign value to certain stimuli over others.

\section{References}

Abbott LF, Nelson SB (2000) Synaptic plasticity: taming the beast. Nat Neurosci [3 Suppl]:1178-1183. CrossRef Medline

Ade KK, Wan Y, Chen M, Gloss B, Calakos N (2011) An improved BAC transgenic fluorescent reporter line for sensitive and specific identification of striatonigral medium spiny neurons. Front Syst Neurosci 5:32. CrossRef Medline

Andersen P, Silfvenius H, Sundberg SH, Sveen O (1980) A comparison of distal and proximal dendritic synapses on CAi pyramids in guinea-pig hippocampal slices in vitro. J Physiol 307:273-299. CrossRef Medline

Bateup HS, Santini E, Shen W, Birnbaum S, Valjent E, Surmeier DJ, Fisone G, Nestler EJ, Greengard P (2010) Distinct subclasses of medium spiny neurons differentially regulate striatal motor behaviors. Proc Natl Acad Sci U S A 107:14845-14850. CrossRef Medline

Berridge KC, Robinson TE (1998) What is the role of dopamine in reward: hedonic impact, reward learning, or incentive salience? Brain Res Brain Res Rev 28:309-369. CrossRef Medline

Bliss TV, Lomo T (1973) Long-lasting potentiation of synaptic transmission in the dentate area of the anaesthetized rabbit following stimulation of the perforant path. J Physiol 232:331-356. CrossRef Medline

Bromberg-Martin ES, Matsumoto M, Hikosaka O (2010) Dopamine in motivational control: rewarding, aversive, and alerting. Neuron 68:815-834. CrossRef Medline

Cahill E, Pascoli V, Trifilieff P, Savoldi D, Kappès V, Lüscher C, Caboche J, Vanhoutte P (2014) $\mathrm{D}_{1} \mathrm{R} / \mathrm{GluN} 1$ complexes in the striatum integrate dopamine and glutamate signalling to control synaptic plasticity and cocaineinduced responses. Mol Psychiatry 19:1295-1304. CrossRef Medline

Calabresi P, Picconi B, Tozzi A, Di Filippo M (2007) Dopamine-mediated regulation of corticostriatal synaptic plasticity. Trends Neurosci 30:211219. CrossRef Medline

Cardin JA, Carlén M, Meletis K, Knoblich U, Zhang F, Deisseroth K, Tsai LH, Moore CI (2009) Driving fast-spiking cells induces gamma rhythm and controls sensory responses. Nature 459:663-667. CrossRef Medline

Debanne D, Poo MM (2010) Spike-timing dependent plasticity beyond synapse-pre- and post-synaptic plasticity of intrinsic neuronal excitability. Front Synaptic Neurosci 2:21. CrossRef Medline

Dreyer JK, Herrik KF, Berg RW, Hounsgaard JD (2010) Influence of phasic and tonic dopamine release on receptor activation. J Neurosci 30:1427314283. CrossRef Medline

Gertler TS, Chan CS, Surmeier DJ (2008) Dichotomous anatomical properties of adult striatal medium spiny neurons. J Neurosci 28:1081410824. CrossRef Medline

Hoffman DA, Magee JC, Colbert CM, Johnston D (1997) K+ channel regulation of signal propagation in dendrites of hippocampal pyramidal neurons. Nature 387:869-875. CrossRef Medline

Kapur S (2003) Psychosis as a state of aberrant salience: a framework linking biology, phenomenology, and pharmacology in schizophrenia. Am J Psychiatry 160:13-23. CrossRef Medline

Kerr JN, Wickens JR (2001) Dopamine D-1/D-5 receptor activation is required for long-term potentiation in the rat neostriatum in vitro. J Neurophysiol 85:117-124. Medline
Koechlin E, Burnod Y (1996) Dual population coding in the neocortex: a model of interaction between representation and attention in the visual cortex. J Cogn Neurosci 8:353-370. CrossRef Medline

Kreitzer AC (2009) Physiology and pharmacology of striatal neurons. Annu Rev Neurosci 32:127-147. CrossRef Medline

Kreitzer AC, Malenka RC (2008) Striatal plasticity and basal ganglia circuit function. Neuron 60:543-554. CrossRef Medline

Lipowsky R, Gillessen T, Alzheimer C (1996) Dendritic Na+ channels amplify EPSPs in hippocampal CA1 pyramidal cells. J Neurophysiol 76: 2181-2191. Medline

Ljungberg T, Apicella P, Schultz W (1992) Responses of monkey dopamine neurons during learning of behavioral reactions. J Neurophysiol 67:145163. Medline

Magee JC (1998) Dendritic hyperpolarization-activated currents modify the integrative properties of hippocampal CAl pyramidal neurons. J Neurosci 18:7613-7624. Medline

Mansour A, Meador-Woodruff JH, Bunzow JR, Civelli O, Akil H, Watson SJ (1990) Localization of dopamine $\mathrm{D}_{2}$ receptor mRNA and $\mathrm{D}_{1}$ and $\mathrm{D}_{2}$ receptor binding in the rat brain and pituitary: an in situ hybridizationreceptor autoradiographic analysis. J Neurosci 10:2587-2600. Medline

Parlato R, Rieker C, Turiault M, Tronche F, Schütz G (2006) Survival of DA neurons is independent of CREM upregulation in absence of CREB. Genesis 2000 44:454-464. CrossRef Medline

Planert H, Berger TK, Silberberg G (2013) Membrane properties of striatal direct and indirect pathway neurons in mouse and rat slices and their modulation by dopamine. PLoS One 8:e57054. CrossRef Medline

Redgrave P, Gurney K (2006) The short-latency dopamine signal: a role in discovering novel actions? Nat Rev Neurosci 7:967-975. CrossRef Medline

Reynolds JN, Hyland BI, Wickens JR (2001) A cellular mechanism of reward-related learning. Nature 413:67-70. CrossRef Medline

Schultz W (1986) Responses of midbrain dopamine neurons to behavioral trigger stimuli in the monkey. J Neurophysiol 56:1439-1461. Medline

Shan Q, Ge M, Christie MJ, Balleine BW (2014) The acquisition of goaldirected actions generates opposing plasticity in direct and indirect pathways in dorsomedial striatum. J Neurosci 34:9196-9201. CrossRef Medline

Shen W, Flajolet M, Greengard P, Surmeier DJ (2008) Dichotomous dopaminergic control of striatal synaptic plasticity. Science 321:848-851. CrossRef Medline

Shu Y, Hasenstaub A, McCormick DA (2003) Turning on and off recurrent balanced cortical activity. Nature 423:288-293. CrossRef Medline

Shusterman R, Smear MC, Koulakov AA, Rinberg D (2011) Precise olfactory responses tile the sniff cycle. Nat Neurosci 14:1039-1044. CrossRef Medline

Steinberg EE, Keiflin R, Boivin JR, Witten IB, Deisseroth K, Janak PH (2013) A causal link between prediction errors, dopamine neurons and learning. Nat Neurosci 16:966-973. CrossRef Medline

Surmeier DJ, Song WJ, Yan Z (1996) Coordinated expression of dopamine receptors in neostriatal medium spiny neurons. J Neurosci 16:6579_ 6591. Medline

Uchida N, Poo C, Haddad R (2014) Coding and transformations in the olfactory system. Annu Rev Neurosci 37:363-385. CrossRef Medline

Wesson DW, Wilson DA (2010) Smelling sounds: olfactory-auditory sensory convergence in the olfactory tubercle. J Neurosci 30:3013-3021. CrossRef Medline

Wesson DW, Wilson DA (2011) Sniffing out the contributions of the olfactory tubercle to the sense of smell: hedonics, sensory integration, and more? Neurosci Biobehav Rev 35:655-668. CrossRef Medline

Wickens JR, Begg AJ, Arbuthnott GW (1996) Dopamine reverses the depression of rat corticostriatal synapses which normally follows high-frequency stimulation of cortex in vitro. Neuroscience 70:1-5. CrossRef Medline

Wieland S, Du D, Oswald MJ, Parlato R, Köhr G, Kelsch W (2014) Phasic dopaminergic activity exerts fast control of cholinergic interneuron firing via sequential NMDA, $D_{2}$, and $D_{1}$ receptor activation. J Neurosci 34: 11549-11559. CrossRef Medline

Yagishita S, Hayashi-Takagi A, Ellis-Davies GC, Urakubo H, Ishii S, Kasai H (2014) A critical time window for dopamine actions on the structural plasticity of dendritic spines. Science 345:1616-1620. CrossRef Medline

Zelano C, Bensafi M, Porter J, Mainland J, Johnson B, Bremner E, Telles C, Khan R, Sobel N (2005) Attentional modulation in human primary olfactory cortex. Nat Neurosci 8:114-120. CrossRef Medline 